\title{
Biomedical Potential of Plant-Based Selenium Nanoparticles: A Comprehensive Review on Therapeutic and Mechanistic Aspects
}

REVIEW

This article was published in the following Dove Press journal: International Journal of Nanomedicine

\section{Muhammad Ikram* \\ Bilal Javed (D* \\ Naveed lqbal Raja \\ Zia-ur-Rehman Mashwani (iD}

Department of Botany, PMAS Arid

Agriculture University, Rawalpindi, Punjab

46300, Pakistan

*These authors contributed equally to this work

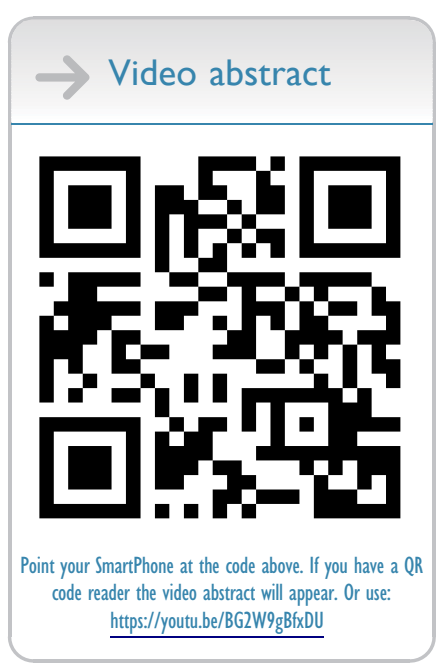

Correspondence: Bilal Javed

Email javedbila187@gmail.com

Muhammad Ikram

Email ikramgondal464@gmail.com

\begin{abstract}
Selenium nanoparticles (SeNPs) have advantages over other nanomaterials because of the promising role of selenium in the stabilization of the immune system and activation of the defense response. The use of SeNPs and their supplements not only have pharmacological significance but also boost and prepare the body's immune system to fight the pathogens. This review summarizes the recent progress in the biogenesis of plant-based SeNPs by using various plant species and the role of secondary metabolites on their biocompatible functioning. Phyto-synthesis of SeNPs results in the synthesis of nanomaterials of various, size, shape and biochemical nature and has advantages over other routine physical and chemical methods because of their biocompatibility, eco-friendly nature and in vivo actions. Unfortunately, the plant-based SeNPs failed to attain considerable attention in the pharmaceutical industry. However, a few studies were performed to explore the therapeutic potential of the SeNPs against various cancer cells, microbial pathogens, viral infections, hepatoprotective actions, diabetic management, and antioxidant approaches. Further, some of the selenium-based drug delivery systems are developed by engineering the SeNPs with the functional ligands to deliver drugs to the targeted sites. This review also provides up-to-date information on the mechanistic actions that the SeNPs adopt to achieve their designated tasks as it may help to develop precision medicine with customized treatment and healthcare for the ailing population.
\end{abstract}

Keywords: green synthesis, SeNPs, drug delivery, diabetes, cancer, reactive oxygen species

\section{Introduction}

Selenium is an essential trace element required for the normal functioning of the humans' and animals' immune systems and prevents various lethal or degenerative diseases. ${ }^{1,2}$ Selenium is reported as an important element and acts as the cofactor and coenzyme of catalytic-active sites' of various selenoproteins and enzymes in the human body and provides protection to cells and tissues from oxidative injuries and stress. ${ }^{3,4}$ Selenium also plays a significant role in the iodine and peroxides metabolism in the body, regulates the level of iodine and free radicals, and can enhance disease resistance. 5,6 The deficiency of selenium disturbs the cellular equilibrium between oxidants and antioxidants, which can exacerbate the oxidation-associated risks, especially when the body is challenged by severe oxidative stresses. ${ }^{3,4}$ Many hepatic degenerative diseases caused by the deposition of toxic elements, heavy metals, alcohol consumption, and administration of chemotherapeutic drugs can be attenuated by the consumption of selenium supplements. ${ }^{3,7,8}$ Selenium is gaining the attention of 
researchers and clinicians because of its excellent antioxidative properties. Furthermore, the deficiency of selenium may cause cardiac, osseous, muscular and immune-related disturbances in the human body. ${ }^{9}$ However, it is very important to meet the daily requirement of this valuable nutrient by selenium supplementation, especially for those individuals which are subjected to selenium deficiencies. ${ }^{10}$ The traditional Se material in food supplements or additives were having a major problem of adsorption and bioavailability. The use of SeNPs containing food supplements has advantages to increase the bioavailability and the controlled release of the selenium in organisms body which increase the efficacy and the effectiveness of supplements. SeNPsbased food supplements have attracted great interest as a food additive especially in individuals with selenium deficiency, but also as a therapeutic agent without any significant side effects in medicine. ${ }^{3}$

Unfortunately, a high selenium supplementation can also cause various devastating diseases. The toxicity and the activity of selenium are usually impacted by the high-dose, so it is very important to control the therapeutic dose. ${ }^{11,12}$ Additionally, the high dose of sodium selenite, selenocysteine, and methyl selenium exhibit excellent therapeutic potential but on the other hand has serious toxicity problems. $^{2,13,14}$ Keeping in view, the above-mentioned high doses of selenium problems, nanotechnology has emerged as an ebullient sphere of science that evinces potential therapeutic applications in medical and nonmedical sectors. ${ }^{3}$ The nano-sized selenium has attracted a great deal of interest worldwide as food additives especially, in those individuals suffering from selenium deficiencies but also as an important therapeutic agent without significant side effects in medicine. ${ }^{13,15,16}$ Additionally, the plant-based SeNPs have excellent potential in sensory probe,${ }^{17}$ targeted delivery of therapeutic drugs, ${ }^{18}$ anticancer agents, ${ }^{19}$ detection of heavy metals, ${ }^{20}$ and have significant antimicrobial properties ${ }^{12}$ (Figure 1). Several physical and chemical techniques have been employed, that requires the utilization of various chemical compounds and physical approaches to synthesize SeNPs. Unfortunately, these technologies are costly and result in the association of hazardous chemical residues with nanoparticles which limit the therapeutic application potential of SeNPs in pharmaceutical and medical industries. Therefore, the emerging efforts and studies have been interested in the biological synthesis of SeNPs; resulting in an eco-friendly and non-toxic synthesis approach. The use of the different plant extracts in the biological synthesis of SeNPs is a less toxic, easier and more cost-effective approach as compared to other biological synthesis methods by utilizing microorganism's enzymes especially fungi and bacteria. ${ }^{2,12,21-24}$ Various plant species have been explored successfully for the synthesis of SeNPs.

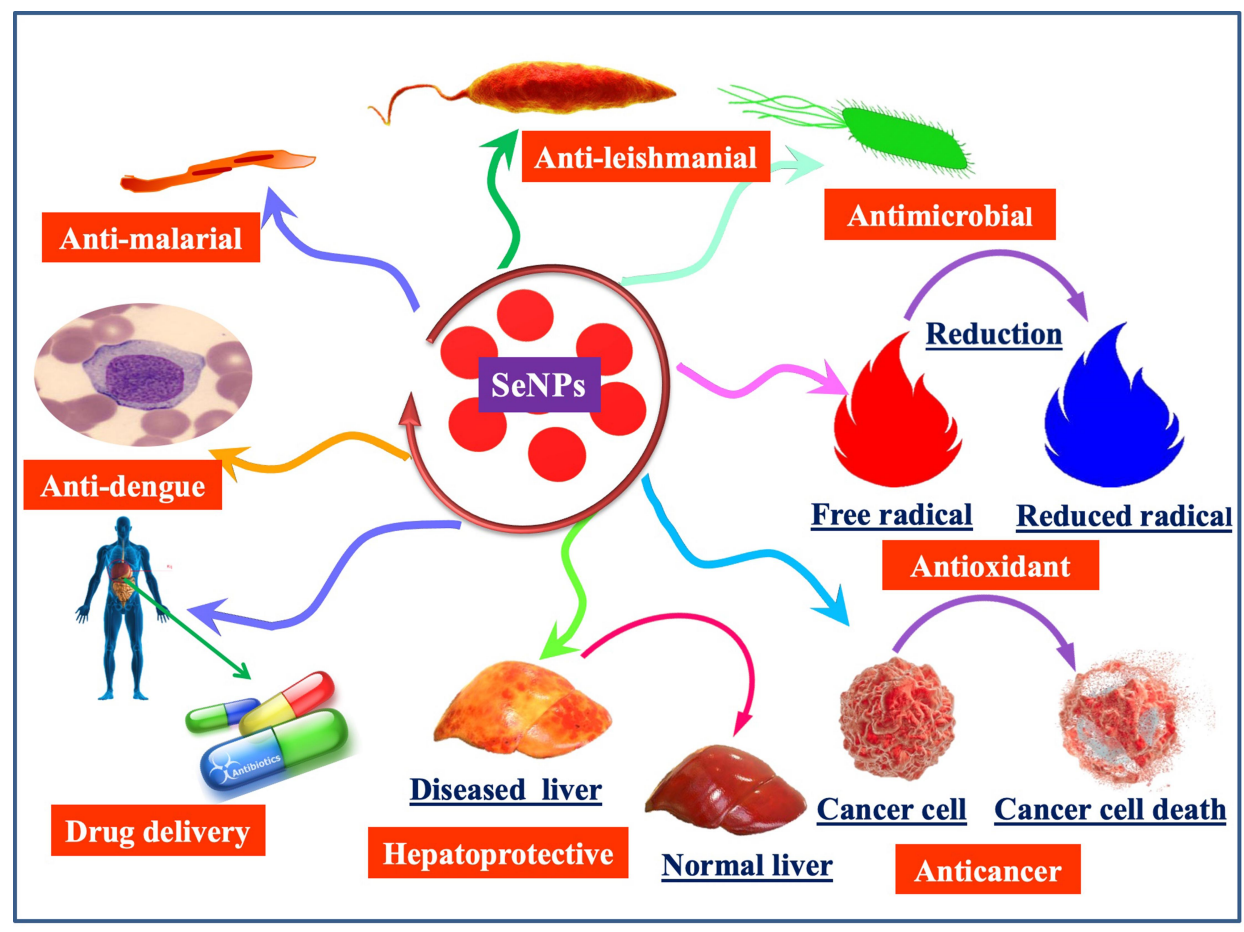

Figure I Diverse application potential of plant-based SeNPs in the medical and pharmaceutical industry. 
The plant extracts contain phenolic acid, sesquiterpenes, cinnamic acid, coumarin, monoterpenes, flavonoids, tannin, alkaloids, and other secondary metabolites which can act as both reducing and potential stabilizing agents in the synthesis of biocompatible SeNPs. ${ }^{25-30}$

This review article focuses on the fabrication methodologies with a focus on plant-based synthetic approaches, morphological significance and diverse application potential of the plant-based SeNPs. Furthermore, this manuscript also provides detail on various mechanistic approaches that the plant-based SeNPs adopt to ameliorate human medical conditions. A detailed overview of the study is given in Scheme 1.

\section{Synthesis of Plant-Based SeNPs and Other Alternative Approaches}

SeNPs can be prepared by using physical, chemical and biological synthesis methods. The chemical synthesis of nanomaterials involves the use of various hazardous chemical substances for the reduction of sodium selenite salt $\left(\mathrm{Na}_{2}\right.$ $\mathrm{SeO}_{3}$ ) into $\mathrm{Se}^{\circ} .^{23,31,32}$ The reference ${ }^{33}$ reported the use of the ascorbic acid solution in the presence of polysaccharides to reduce the selenious acid $\left(\mathrm{H}_{2} \mathrm{SeO}_{3}\right)$ into SeNPs of different sizes and unique morphologies. Ascorbic acid was used as a reducing agent while the polysaccharides were utilized to stabilize the nano-selenium core. Similarly, many other studies reported the use of Quercetin, Gallic acid and extracellular polymeric substances to synthesize SeNPs. ${ }^{1,32}$ Additionally, the reference ${ }^{34}$ reported the synthesis of SeNPs by reacting the ionic liquid with the sodium selenosulfate salt $\left(\mathrm{Na}_{2} \mathrm{O}_{3} \mathrm{SSe}\right)$ in the presence of polyvinyl alcohol as a stabilizing agent. The other physical and chemical methods of the synthesis of SeNPs also include the $\mathrm{pH}$, light, sound assisted, and the temperature stimulated reduction of sodium selenite salts into SeNPs. Various studies revealed the physical methods to synthesize SeNPs by

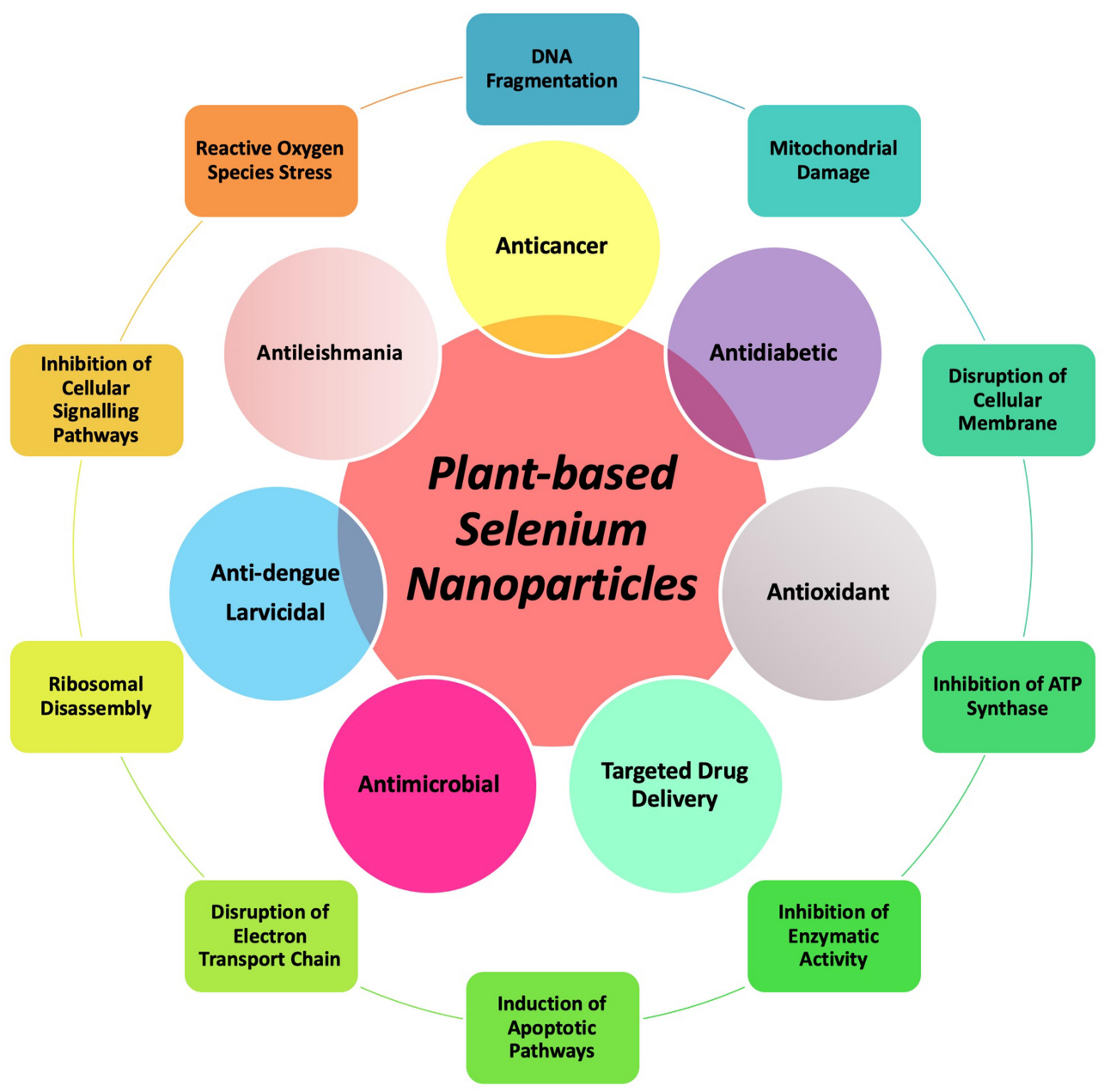

Scheme I Pictorial overview of the study. The inner circle explains the biomedical potential of plant-based SeNPs while the outer circle explains the mechanistic approaches of SeNPs. 
using pulsed laser ablation strategy and ultrasound-assisted synthesis $^{35}$ (Figure 2). Unfortunately, the physical and chemical methods of nanoparticle synthesis have been increasingly disfavored due to the cost-ineffectiveness and various other important environmental biosafety and toxicity concerns. To cope with these issues, the biosynthesis of SeNPs has been recommended as a viable conventional alternative strategy. $^{23}$

The biosynthesis of SeNPs includes the use of living materials such as plants, algae, fungi and bacteria for the reduction of $\mathrm{Na}_{2} \mathrm{SeO}_{3}$ to SeNPs. The reference ${ }^{36}$ used the fungus Mariannaea species for the synthesis of SeNPs. Similarly, various bacterial species, such as Pseudomonas aeruginosa $^{32}$ and Klebsiella pneumoniae ${ }^{37}$ have been explored for the synthesis of SeNPs.

Among other biosynthesis methods, the plants-based synthesis of SeNPs has advantages over routine or conventional synthesis approaches due to their sound biomedical nature. The plant-based synthesis of SeNPs is an eco-friendly and economic strategy that involves the natural stabilizing and reducing agents (Figure 2). The plant extract mediated synthesis of nanomaterials started at the beginning of the 20th century and several plant species have been explored for their potential to reduce and stabilize SeNPs. The reference $^{38}$ demonstrated the use of Aloe vera leaf extract for the biosynthesis of SeNPs. It was demonstrated that the Aloe vera leaf extract possesses numerous natural reductants and stabilizers like sterols, polysaccharides, vitamins, phenolic compounds, organic acids, enzymes, lignin, flavonoids and proteins that belong to the plant secondary metabolites and function in the reduction of Se salt. These compounds play a significant role in the green synthesis and stabilization of SeNPs. ${ }^{39,40}$ However, keeping in view the importance of eco-friendly extracellular green synthesis of stable SeNPs various experiments were performed by using plant extracts from various plant parts like root, shoot, bark, stem, and flower. Moreover, the reference ${ }^{41}$ also reported the green synthesis of SeNPs by using Vitis vinifera (raisin) extract as a reducing and stabilizing agent. For instance, the reference ${ }^{17}$ reported the green synthesis of SeNPs of various sizes and shapes in the presence of garlic cloves extract (Allium sativum). Similarly, many other studies have been described to explore the biosynthesis of SeNPs by using the leaf extracts of Dillenia indica, ${ }^{42}$ Spermacoce hispida aqueous leaf extract, ${ }^{19}$ Zingiber officinale fruit extract, ${ }^{43}$ Carica papaya latex, ${ }^{44}$ Citrus lemon fresh fruit extract, ${ }^{45}$ Roselle plant extract, $^{46}$ Cinnamomum zeylanicum bark extract and Prunus amygdalus leaves extract. ${ }^{47}$ Furthermore, the reference $^{48}$ reported spherical shaped SeNPs with a 15-20 nm size range by using Ocimum tenuiflorum leaf extract

\section{Methods of Selenium Nanomaterials Synthesis}

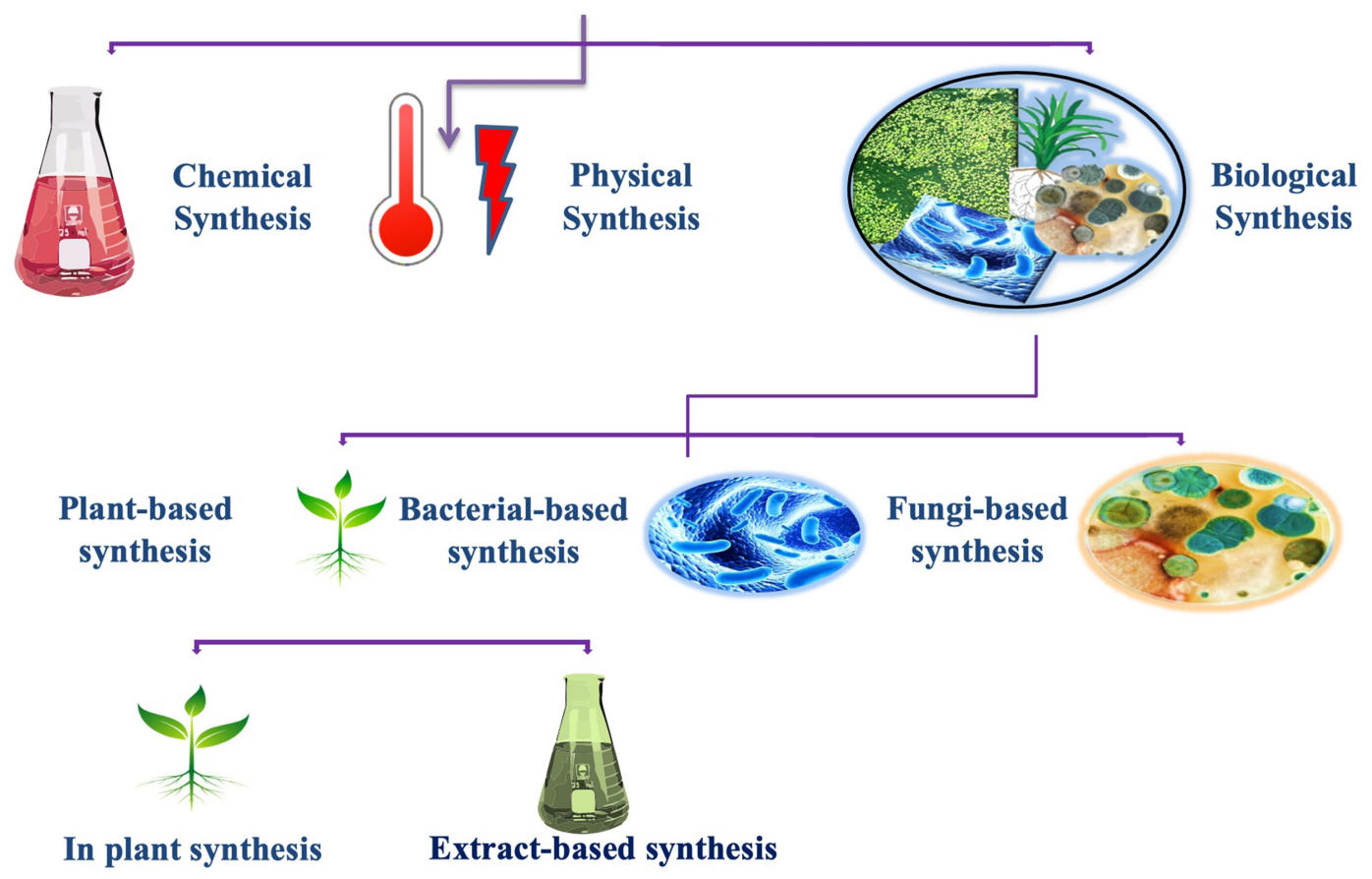

Figure 2 Different routes for the synthesis of SeNPs. 
(Figure 3). The versatility, stability and biocompatibility of SeNPs also depend on the type of plant extract used, its optimized concentration, and physicochemical reaction parameters representing different surface Plasmon resonance bands (SPR). ${ }^{12}$ However, the production of plant-based SeNPs at the industrial scale requires the optimization of the protocol to synthesize nanoparticles of similar size and shape. It also requires the control of physicochemical parameters of the reaction conditions to optimize synthesis. The size, shape and biochemical corona of SeNPs determine their potential biomedical applications which depend on the reaction conditions. However, the production of plant-based nanomaterials at the industrial stage is still in the process of development as it requires an extensive understanding of the mechanism of reduction of selenium salt by using plant secondary metabolites and the synergistic response of reaction physicochemical parameters.

\section{Biomedical Application Potential of Plant-Based SeNPs Biomedical Potential of Plant-Based SeNPs to Treat Cancer}

Cancer is reported as the second most leading cause of death worldwide, accounting for 9.6 million deaths in 2018. Cancer is usually caused by mutations in protooncogenes and key tumor suppressor genes. ${ }^{30}$ Lung, stomach, liver, prostate, colorectal, cervical, thyroid and breast cancer are common in humans. Among these, breast cancer is the most prevalent among women and prostate

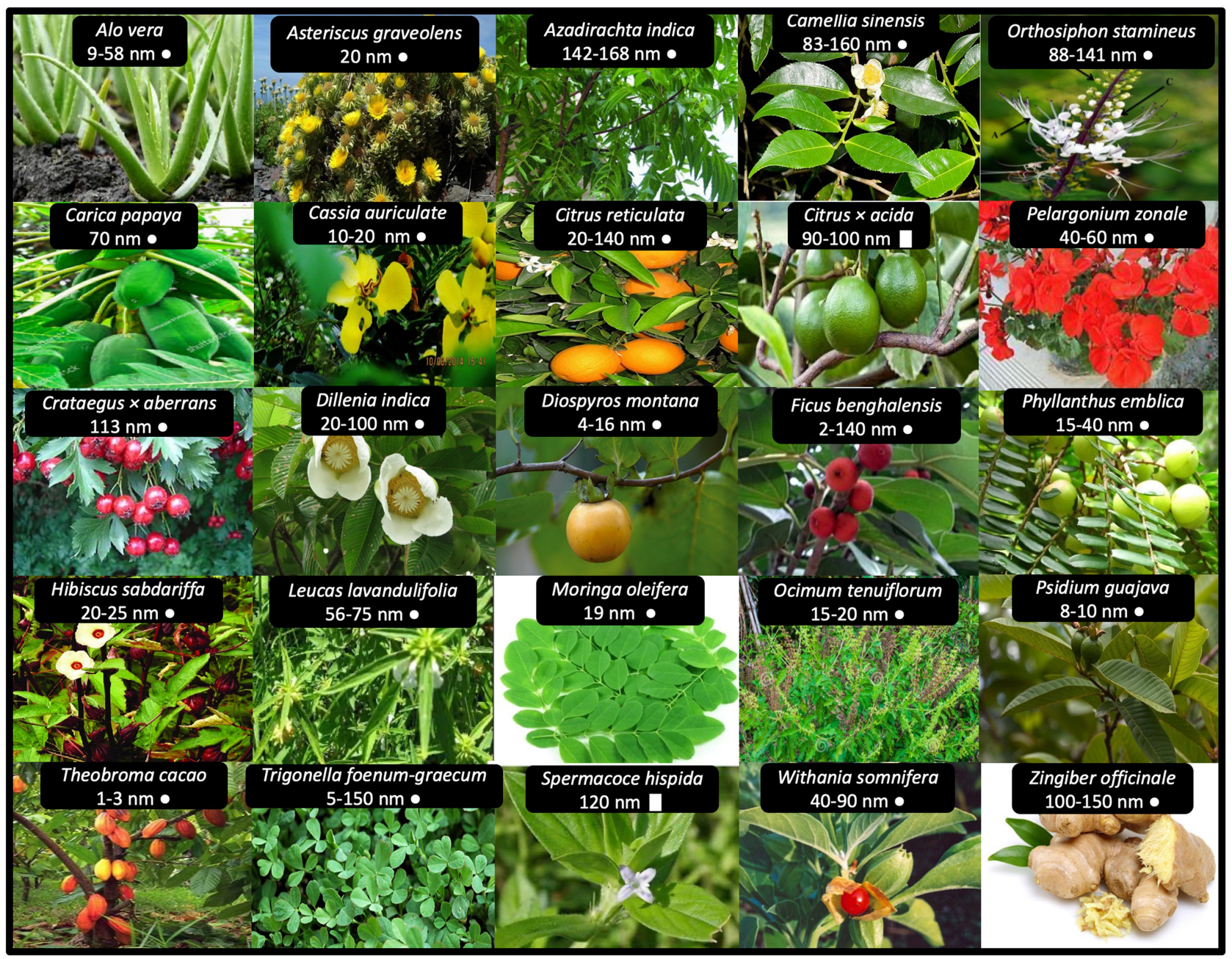

: Rod shaped nanomaterial, •: Spherical shaped nanomaterial

Figure 3 Photographic images of plant materials used previously for the biogenesis of plant-based SeNPs. 
cancer among men globally. ${ }^{4,50}$ The conventional cancer treatment involves the surgical removal of the cancerous parts, the chemotherapeutic killing of the cancer cells, endocrine therapy and the radioactive elimination of the deadliest cancer cells. There are some other less significant additional approaches to treat cancer or tumor cells that involves hormone therapy and immunotherapy but these treatments often lead to cause abnormalities in the patient's body resulting in the damage of many normal cells and important organs of the patients owing to a decrease in the quality of life. ${ }^{49,51,52}$

The cancer cells differ biologically as compared to normal living cells, in their behavior such as proliferating blood vessels which is called angiogenesis and less permeability of capillaries and lymph drainage system. Nanotechnologists use this diverse microenvironment of the cancer cells as an opportunity to engineer effective nanodrugs to treat cancer cells selectively and precisely. ${ }^{53,54}$ Cancer nanobiotechnology has the potential to alter the approaches of cancer detection, diagnosis and treatment. Plant-based SeNPs have been routinely tested against various cancer cells including human breast cancer cells, human colon adenocarcinoma, Ehrlich Ascites Carcinoma and liver cancer cells. ${ }^{55}$

The plant-based SeNPs have shown promising anticancer properties when their different concentrations were applied to other human cancer cell lines like liver cancer, human cervical carcinoma cells and lung cancers. The efficacy of the plant-based SeNPs is still needed to be explored against ovarian cancer, leukemia cancer, colon cancer, skin cancer, prostate cancer (one of the most destructive common cancer in elderly men globally) and the most significant brain gliomas that starts in glial cells of the brain. ${ }^{56}$ The plant-based SeNPs can be explored in the future to treat these gliomas especially in cases where it is impossible to make excisions (brain stem glioma). The plant-based SeNPs can also be explored for the targeted drug delivery applications to treat these devastating gliomas. The plant-based SeNPs synthesized at neutral $\mathrm{pH}$, having a small size and spherical shape are effective anticancerous agents (Figure 4). ${ }^{22}$ A study revealed that the stability of the plant-based SeNPs is due to the presence of alkaloids, amino acids, cardiac glycosides, saponins, flavonoids, phenols, flavanols, polysaccharides and galactomannan in the plant extract that function to stabilize the biochemical corona of nanomaterial. These chemical compounds further increase the applicability and the potential of the plant-based SeNPs as a possible future solution to combat the devastating effects of different cancer cells. ${ }^{55}$

In another study, it was demonstrated that the SeNPs prepared by using laminarin polysaccharides (LP-SeNPs) exhibited a spherical structure with an average diameter of $60 \mathrm{~nm}$ and have the potential to induce toxicity in human liver carcinoma (HepG2) cells. It was later explained that the LP-SeNPs activate different mitochondrial pathways to induce apoptosis and inhibiting the late phase of autophagy. The plant-based SeNPs was also reported to decrease the expression of anti-apoptotic factor Bcl-2 and alleviate the inhibitory effects of Bcl-2 (B-cell lymphoma 2) on Beclin-1 in human liver carcinoma cells. ${ }^{57}$ The SeNPs have the potential to increase oxidative stress and inflammation by producing reactive oxygen species, thereby decrease the percent cell viability. ${ }^{1}$ Plant-based SeNPs significantly increase the level of ROS and decrease the mitochondrial potential and glutathione level, thus regulating the fate of HepG2 cells. It was manifested that the inhibition of HepG2 cell proliferation is due to the DNA damage in HepG2 cells which was caused by the SeNPs and ultimately results in the cell cycle arrest (Figure 5). ${ }^{58}$

Phyto-fabrication of SeNPs by using the leaf extract of Withania somnifera is known to reduce the viability of adeno-carcinomic human alveolar basal epithelial cancer cells (AJ 549). It was explained that the SeNPs induce chromosomal instability and mitotic arrest in the human alveolar basal cancer cells. ${ }^{23}$ Another study showed that the breast cancer cells were severely impacted by Carica papaya latex mediated SeNPs due to apoptotic changes such as the formation of the apoptotic body in the breast cancer cells, chromatic condensation and fragmentation. Notable alterations in nuclear morphology and significant events like nuclear condensation happen by the plants-based SeNPs which causes cytotoxicity in the cancer cells. ${ }^{44}$

The biosynthesized SeNPs have excellent antileukemia potential. It was demonstrated that the biosynthesized SeNPs significantly inhibit the proliferation of the acute myeloid leukemia cells (AML) by increasing the antioxidant potential of AML cells and delimit the expression of c-Jun activation domain-binding protein 1 and thioredoxin 1. ${ }^{5}$ Another mechanism responsible for the anti-leukemia potential of SeNPs involves the effective removal of the free radicals by selenium nanoparticles, thus inhibit the lipid peroxidation induced by free radicals (Figure 5). ${ }^{15}$ Unfortunately, only a few studies have reported the anticancer potential of the plant-based SeNPs on human AML cells. By keeping in view the 


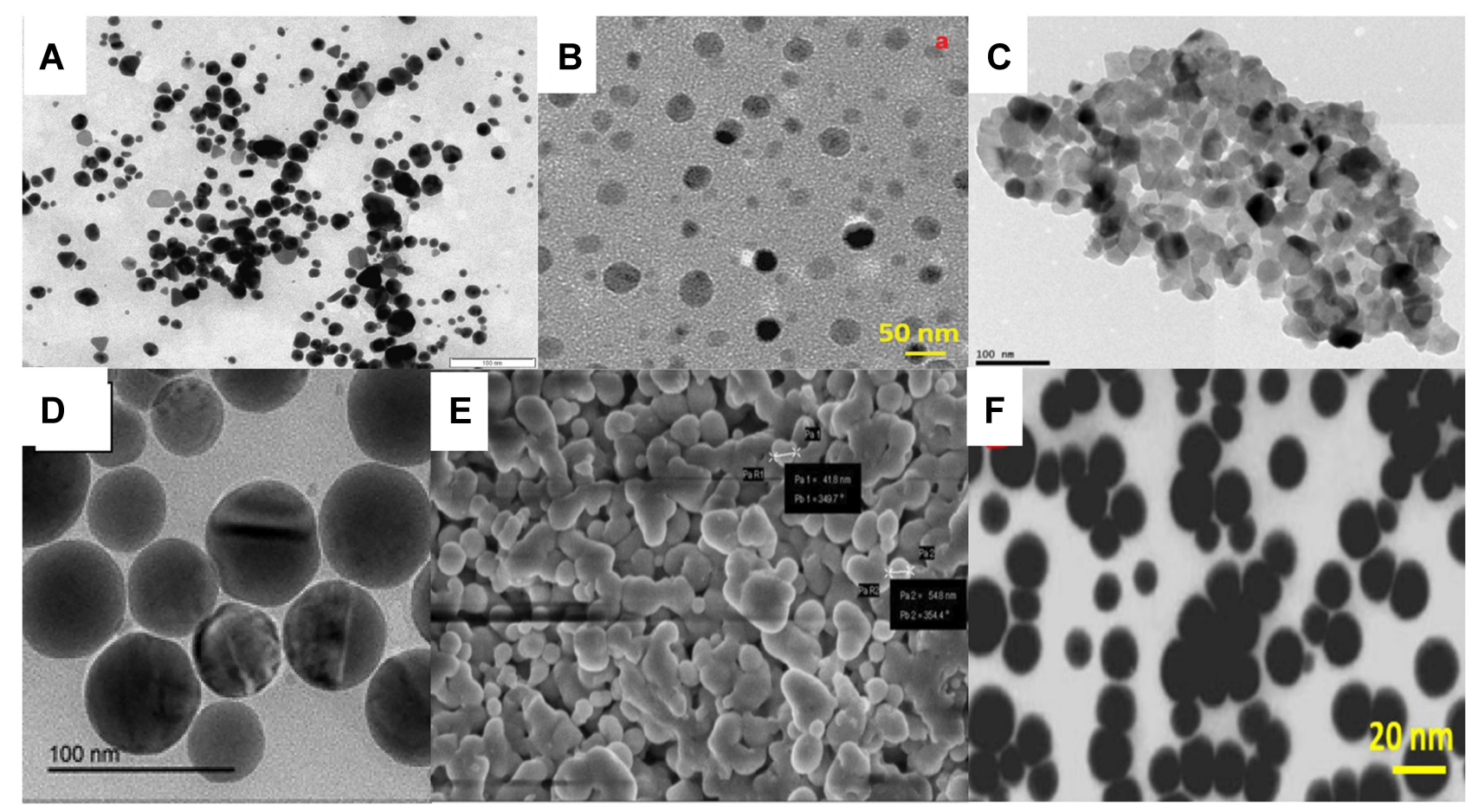

Figure 4 Different micrographic images of the plant-based SeNPs representing nanoparticles of various shapes and sizes. The images are adapted from the references. $^{14,23,46,48,76}$ (A) SeNPs synthesized from Cassia auriculata (B) SeNPs synthesized from Hibiscus sabdariffa (C) SeNPs synthesized from Emblica officinalis (D) SeNPs synthesized from Catathelasma ventricosum (E) SeNPs synthesized from Withania somnifera (F) SeNPs synthesized from Ocimum tenuiflorum.

antioxidant potential and cytotoxic effects of the plantbased SeNPs on cancer cells, these can be explored for the development of effective chemotherapeutic drugs.

Plant-based SeNPs enters the cells by receptors mediated endocytosis. The malignant cells have a specific acidic $\mathrm{pH}$ state with redox imbalance. SeNPs trigger the further formation of free radicals which on one hand disrupts the mitochondrial membrane that results in leakage of mitochondrial proteins and on the other side causes endoplasmic reticulum stress. The mitochondrial membrane disruption leads to the leakage of various proteins and triggers apoptosis through the activation of caspases. This cellular stress state manages the activation process of various molecular pathways including the NF- $\mathrm{BB}, \mathrm{Wnt} / \beta$-catenin, MAPK/Erk, PI3K/Akt/mTOR and apoptotic pathways. The NF- $\kappa \mathrm{B}$ disrupts cellular homeostasis via oxidative and inflammatory stress signaling system. On the other hand, the MAPK/Erk, VEGF, PI3K/Akt/ mTOR, and Wnt/ $\beta$-catenin pathways are essential in oncogenic signaling (Figure 5). The modulation of these pathways by plant-based SeNPs causes impaired cellular proliferation and obstructs the growth-promoting signaling in the vicinity of the tumor microenvironment. Additionally, the biosynthesized SeNPs cause a decline in signaling pathways of cancer cells and eventually reduce their proliferation. In the end, the disruptive cellular events initiate DNA fragmentation causing cell cycle arrest which leads to cell death. ${ }^{1}$

\section{Biomedical Potential of Plant-Based SeNPs in Drug Delivery}

Drug delivery involves the administration of pharmaceutical material to the targeted site to achieve therapeutic effects in living organisms. ${ }^{59}$ Some of the most common routes of drug administration include the parenteral (via injections), enteral (gastrointestinal tract) but these administration routes have the problems of drug distribution to both the healthy and abnormal cells. Multidrug resistance and the therapeutic efficiency of current methods of treatment remain the biggest challenge in fighting carcinogenesis. Toxicities associated with the non-specificity of the drug remain a major challenge in the treatment outcomes and overall success rate. ${ }^{60}$ The nanoparticles have gained considerable attention in the field of nanomedicine due to their targeted delivery to the specific sites and cells, biological activity, excellent bioavailability, low toxicity and dual functionality of therapy and diagnosis. ${ }^{61}$ The nanoparticles can be engineered concerning the desired size, gene and drug loading capacity and controlled release. ${ }^{60}$ 


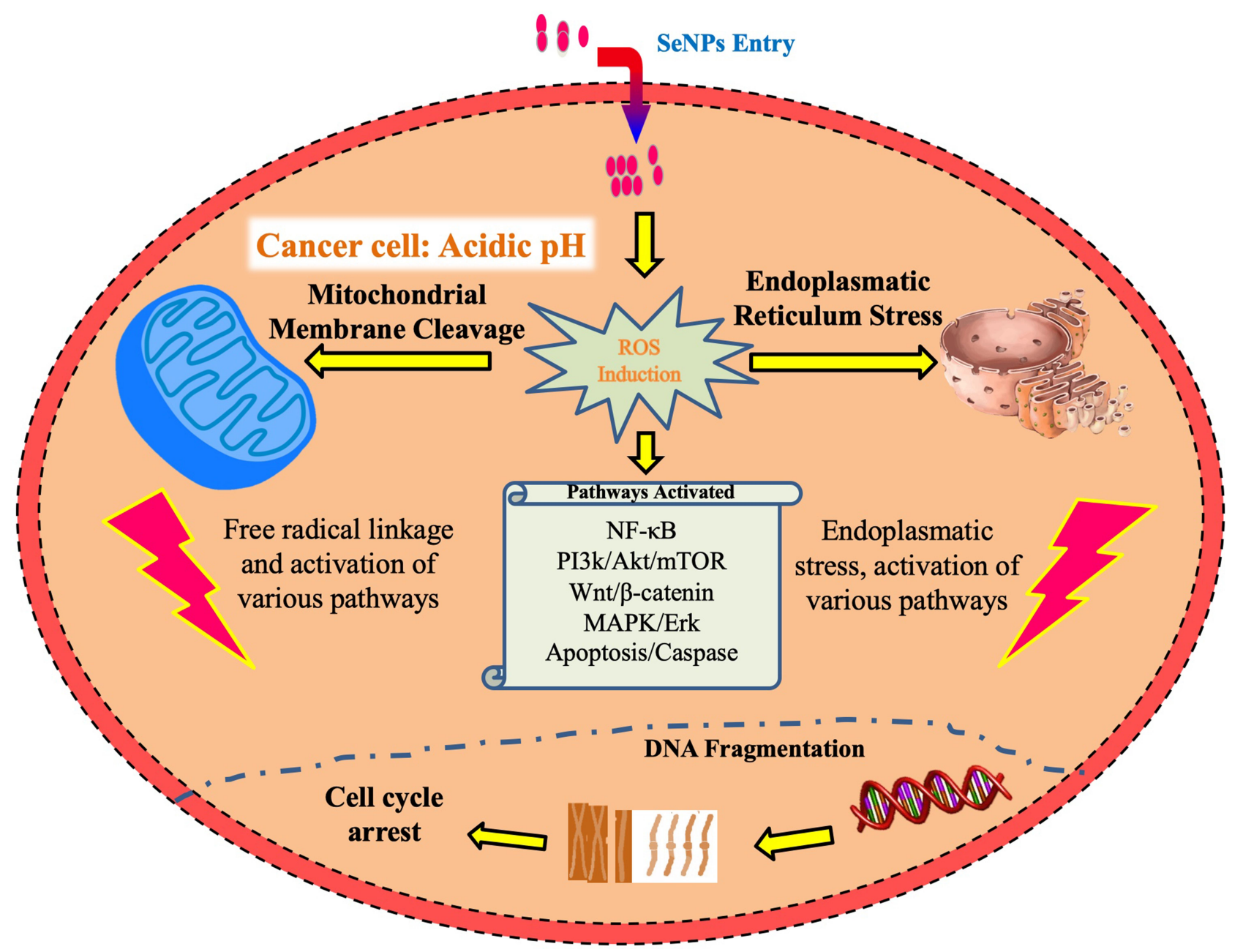

Figure 5 Possible anticancer mechanism of the plant-based SeNPs and different pathways that involve in the cytotoxic potential of SeNPs.

Phyto-fabricated SeNPs are considered superior to other metal nanoparticles, such as platinum, silver, and gold nanoparticles due to their excellent biocompatibility and degradability potential in vivo. Furthermore, the plant-based SeNPs emerged as a novel therapeutic form of selenium finding a niche in the nano-medicine as the delivery vehicles, by the virtue of their unique optical and photoelectric properties. ${ }^{24}$ The plants based SeNPs worked as a good mediator for drug delivery such as bioligands, proteins, genetic material and some biomacromolecules. However, the agglomeration of SeNPs affects biocompatibility, bioavailability, and bioactivity. The surface functionalization of the plant-mediated SeNPs with biologically active ligands not only increase the bioavailability but also synergistically enhance its therapeutic potential. ${ }^{1}$

In recent studies, the plant-based SeNPs have shown remarkable potential as a drug carrier and potent delivering agent of S-allyl-glutathione (SAG). S-allylglutathione (SAG) is an analog of glutathione synthesized by alkylating the thiol group of the glutathione with the allyl group. In past, SAG has shown potent topoisomerase inhibition in vitro as a target protein of the cancer treatment. The SeNPs were synthesized by using the Spermacoce hispida aqueous leaf extract and surface functionalized with SAG to form SAG-ShSeNPs. ${ }^{62}$ Additionally, it was demonstrated that the SAG-Sh-SeNPs stimulate the ROS generation in the cancer cells. After internalization, the SAG-Sh-SeNPs might have separated into SAG and Sh-SeNPs. Both SAG and Sh-SeNPs have the potential to synergistically affect the viability of the cancer cells. ${ }^{19}$

Furthermore, polyamidoamine (PAMAM) modified SeNPs can simultaneously deliver cisplatin and siRNA to the tumor cells without any systemic toxicity. ${ }^{63}$ The biosynthesized SeNPs are also reported as a carrier for the 
delivery of FDA approved anticancer drug doxorubicin. They have been successfully designed to target breast cancer cells with less toxicity and excellent anticancer efficacy as compared to drugs alone. ${ }^{44,50}$

In another study, curcumin loaded SeNPs were explored with promising anticancer potential and were found very efficacious against deadliest Ehrlich's ascites carcinoma by induction of the apoptosis and reduction of NF- $\mathrm{KB}$ signaling and EMT. ${ }^{64,65}$ The anticancer potential of biosynthesized SeNPs increased when they were used in combination with the irinotecan drug which disrupts the mitochondrial membrane and causes DNA damage and nuclear condensation in the cancer cells. ${ }^{8}$

However, the efficacy of the plant-based SeNPs in drug delivery and gene delivery still needs to be checked. Keeping in view, the biocompatibility of biogenic SeNPs it is not too hard to assume that the plant-based SeNPs can be a promising and systematic vehicle in the future for the targeted drug and gene delivery in cancer therapy, cancer imaging and other devastating afflictions.

\section{Antidiabetic Application Potential of Plant-Based SeNPs}

Diabetes is an epidemic metabolic disease that decreases the quality of life of the patients. The World Health Organization reported 1.5 million deaths every year worldwide and the incidence of diabetes disease are expected to be about 366 million by $2030 .{ }^{66}$ Diabetes is dependent on several factors such as unhealthy food habits, stress, low physical activity, obesity, inflammation, genetics, and age. However, there are some measures (e.g. diet intervention, exercise, proper monitoring of blood cholesterol and glucose level and blood pressure) that can be taken to control diabetes and its associated serious complications. ${ }^{46,67,68}$ Insulin is a protein hormone and its subcutaneous injections are used as a first-line treatment to control diabetes. ${ }^{69,70}$ However, the multiple daily insulin injections are associated with pain, discomfort, local infection, and the deposition of the fat at the injection site, hypertrophy and trypanophobia. ${ }^{67}$

Selenium is essential among other trace elements necessary for humans and animals. In the human body, selenium is involved in various processes with immune functions and antioxidant defense systems. ${ }^{9}$ According to the United States National Academy of Sciences, the recommended daily intake of Selenium is $55 \mu \mathrm{g}$ for adults but it should not exceed the threshold limit of $400 \mu \mathrm{g} .{ }^{71}$ On the other hand, a selenium dose greater than $700 \mu \mathrm{g} /$ day is considered to be toxic for adults. ${ }^{46}$ The attention of nanotechnologists in selenium and its beneficial effects on humans and animals is increasing day by day. Plant-based synthesis provides an advantage to prepare nanoparticles of excellent biocompatible nature without adding additional stabilizing and capping agents. ${ }^{17,72}$ Because of its non-toxic nature, it is well agreed that plant-based SeNPs can be one of the alternative strategies to control the deadliest diabetes. Hibiscus sabdariffa (roselle plant) leaf extract mediated SeNPs were synthesized to study the antioxidative effects in streptozotocin (STZ) induced diabetic rats. ${ }^{46}$ Streptozotocin is a broad-spectrum antibiotic drug derived from Streptomyces achromogenes bacterium. ${ }^{65}$ Streptozotocin is also known to be a pancreatic beta-cell specific cytotoxin so that's why it is used to induce diabetes in the rodent models during the experiments. ${ }^{46,65}$ STZ causes an increase in malondialdehyde (MDA) and nitric oxide (NO) levels but it also decreases the antioxidant potential of CAT, SOD, GR, and GPx in rats. Streptozotocin uses specialized receptors GLUT 2 (Glucose transporter 2) receptors, and competes with glucose molecules and causes Akt phosphorylation. Furthermore, STZ induces apoptosis and cytotoxicity by increasing the level of ROS and NOS production. STZ induces oxidative stress that leads to a reduction in testosterone level, mitochondrial cleavage and DNA fragmentation by decreasing the antioxidant potential of CAT, SOD, etc. ultimately leading to cell death. Phyto-fabricated SeNPs used receptors mediated endocytosis for internalization, and it inhibits the production of ROS, NOS, by increasing the antioxidant potential of CAT, POD, and serum testosterone and lipids level in STZ induced rats (Figure 6). ${ }^{14,46,65}$

On the other hand, it was reported that plant-based SeNPs enhance serum testosterone reduction which is caused by STZ induced diabetes. Additionally, the treatment of plant-based SeNPs on STZ induced diabetic rats significantly reduces oxidative stress such as lipid peroxidation. The plant-mediated SeNPs increased the potential of antioxidant enzymes as well as the glutathione content in the testicular tissues. It was also reported that SeNPs have the capability to prevent histological damage in the testes of STZ induced diabetic rats. ${ }^{9,64,73}$

Unfortunately, very few reports are available regarding the anti-diabetic effects of the plant-based SeNPs. In another study, it was reported that the SeNPs prepared by using polysaccharides from the Catathelasma ventricosum could significantly ameliorate the body weight, the blood sugar level, the antioxidant enzyme potential, and lipid level in streptozotocin-induced mice. ${ }^{14}$ It was also manifested that the green synthesized SeNPs improve the insulin 


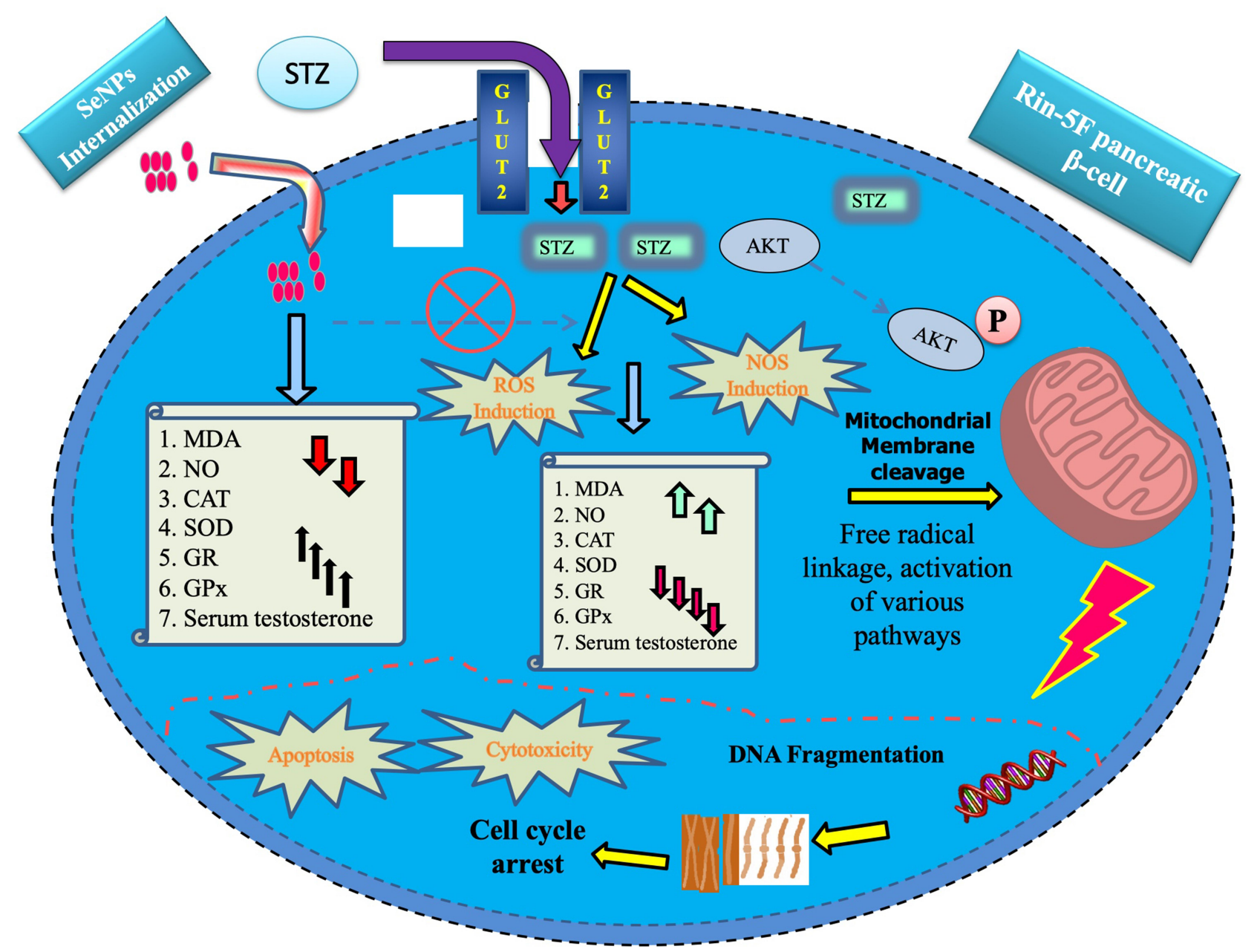

Figure 6 Anti-diabetic mechanism of the plant-based SeNPs against Streptozotocin-induced cytotoxicity and apoptosis in Rin- 5F pancreatic $\beta$-Cells. Note: (Streptozotocin-induced): Upward arrow: Increase, Downward arrow: Decrease. Characters are the opposite in the case of SeNPs.

release and $\beta$-cells proliferation. The proposed mechanism of the SeNPs to fight against diabetes includes the ROS scavenging potential and modulations of HSP70 and SIRT1. ${ }^{1}$ The exact antidiabetic mechanism of the plantmediated selenium nanoparticle is not clearly understood which requires extensive pharmacological and chemical investigation. By keeping in view the excellent antidiabetic potential of the plant-mediated SeNPs in rats and mice, it is not very hard to believe that the plant-based SeNPs may be a useful and efficient tool to develop nanomedicines for the treatment of human diabetes in the future. ${ }^{1,42}$

\section{Antioxidant Application Potential of Plant-Based SeNPs}

The antioxidants play an important role to interact with the free radicals to stabilize them, terminating the adverse chain reactions and convert free radicals into harmless products. Antioxidants significantly balance oxidative stress and play a crucial role in the treatment of free radicals-induced degenerative diseases. However, the natural and synthetic antioxidants have limited effectiveness due to their poor absorption, difficulties to cross the plasma cell membranes, and degradation during delivery, which contributes to their limited bioavailability. However, the plant-based nanoparticles have potential antioxidant functional groups that have better stability, controlled release and biocompatibility with superior antioxidant profiles. ${ }^{74}$ The plant-based SeNPs are well known due to their excellent antioxidant potential as evidenced in previous studies, ${ }^{43,61,75,76}$ where plants-based SeNPs were explored to effectively scavenge the DPPH and ABTS free radicals in lesser time. The excellent antioxidant potential of the plant-based SeNPs is due to a higher level of nanoselenium that plays a significant role in an upturn of selenoenzymes like glutathione peroxidase that helps in 
the protection of cells and tissues in vivo from free radicals. ${ }^{10,15,77,78}$ Additionally, in another study, it was reported that the Mucuna pruriens and Aloe vera based SeNPs show excellent antioxidant potential to protect the cell from the deadliest effects of ROS. ${ }^{38,43}$ The regulatory antioxidant potential of plant-based SeNPs is might be due to the selenium that is a very important constituent of selenoproteins like thioredoxin reductases and glutathione peroxidases that protect cells from oxidative damage. ${ }^{79}$

It was reported that the antioxidant potential of the plants-based SeNPs is may be due to the potential surface functional groups that cap and stabilize the nanoparticles and originate from the plant secondary metabolites. ${ }^{32,62}$ The nutritionists and physicians routinely suggest using selenium supplemented food sources (nuts, mushrooms and cereals) to stay healthy. ${ }^{13,71}$ The plants-based SeNPs are considered highly biocompatible in substituting the synthetic antioxidants as natural antioxidant embedding agents in food packaging material. ${ }^{15,72}$ By keeping in view, the significance of phyto-fabricated SeNPs, it is not very difficult to believe that these NPs can be promising futuristic candidates for the cosmetic industries where they can be used in anti-aging creams and sunscreen agents. The plant-based SeNPs have their potential applications in most coronary heart disease, cancer and osteoporosis results due to oxidative stress caused by the ROS. ${ }^{44}$

\section{Antimicrobial Application Potential of Plant-Based SeNPs}

The use of medicinal plants and their products as a source of biomedicine has been a conventional approach to treat microbial diseases. ${ }^{80}$ Since the development of various antibiotics in the early 20th century, it had been the frontline therapy against various Gram-negative and Gram-positive bacterial infections. ${ }^{81}$ The majority of the antibiotics target bacterial ribosomes and stop their growth or disassemble ribosomal units by altering the translation process. ${ }^{82}$ Many antibiotics are known to cause several side effects in humans and animals. According to the endosymbiotic theory, the mitochondrion is of bacterial origin and their structural and molecular components of the protein expression system are nearly similar. Due to similarities between mitochondrial and bacterial ribosomes, varieties of antibiotics show side effects similar to mitochondrial myopathies. ${ }^{81,83}$ It is reported that the lethal doses of bactericidal antibiotics may lead to mutations and biochemical changes in the host cell and induce the formation of highly harmful oxidative radical species. ${ }^{84}$

The emergence of antibiotics resistance in the majority of pathogenic bacterial strains is a cause of utmost concern in infectious bacterial diseases. Therefore, there is an inevitable need to identify the effective antimicrobial agents which are more effective against microbial ailments with minimal side effects on host cells. Selenium (Se) is considered a potent antimicrobial agent, and its derivative substance like selenium sulfide is extensively used in medicine to treat infections of microorganisms. ${ }^{47,85}$ However, overuse of Se causes toxic effects and leads to selenosis, which limits the use of elemental Se for therapeutic purposes. ${ }^{71,76}$ Consequently, contemporary research has focused on diminishing the toxicity and improving the bio-functional aspects of selenium. ${ }^{86}$ In this scenario, nanotechnology has provided the best safety strategy to reduce the toxicity and improve the bio-functionality of selenium through green synthesis. Besides, plant-based SeNPs are considered better than elemental selenium because of their excellent antimicrobial potential and biocompatibility. ${ }^{21,38,76}$

However, further research is required to develop plantbased SeNPs having non-toxic nature, excellent antimicrobial activity at a low dose and bioactivity. The plant-based SeNPs have been well explored as antimicrobial potential agents. The specific antimicrobial property of the plantmediated SeNPs might be due to their smaller size as the compared size of microorganisms which helps them to enter the cell membrane of microorganisms and causes cell death. $^{43,75}$

Another study reported that the plant-mediated SeNPs with smaller size and spherical shape had easy access into the bacterial cell, that's why it is well agreed upon that antimicrobial potential of the plant-based SeNPs is inversely proportional to its size which increases with decreases in the size of plant-mediated SeNPs. ${ }^{87}$ Plant-based SeNPs are well known to be active against both Gram-positive (Staphylococcus aureus) and Gram-negative (Proteus sp, Escherichia coli and Klebsiella pneumonia) bacterial strains but it seems that SeNPs are more effective against Gram-negative bacteria because of their thin peptidoglycan cell wall. Furthermore, it was also demonstrated that the SeNPs synthesized by using Psidium guajava leaf extract are well reported for their antibacterial potential which showed excellent antibacterial activity against Staphylococcus aureus and Escherichia coli. ${ }^{12}$

The plant-based SeNPs are also found active against different human pathogenic fungi. It was reported that the SeNPs 
synthesized by using fruit extract of Phyllanthus emblica having antimicrobial potential against foodborne pathogens including, Listeria monocytogenes, Aspergillus brasiliensis, Aspergillus flavus, Aspergillus oryzae, Fusarium anthophilum, Aspergillus niger and Rhizopus stolonifer. ${ }^{21,38,76}$

The antimicrobial potential of plant-based SeNPs is may be due to two reasons such as the production of the reactive oxygen species or through disruption of the cell membrane integrity. Another mechanism of the plant-mediated SeNPs is to inhibit the growth of microorganisms by breaking cell wall then binds to the cell membrane and altering DNA replication, food metabolism cycle, protein synthesis cycle ultimately binds with thiol or sulfhydryl groups present in the membrane proteins and thus causes denaturation in them leading to cell death (Figure 7). However, the exact antimicrobial mechanism of plant-based SeNPs still needs to be explored. ${ }^{9,87,88}$

The small size and the biochemical attributes of the nanoparticles provide them advantages to be toxic against pathogens. The potential functional groups of nanoparticles also help them to cross the plasma cell membrane of the bacterial cell. The overall charge on nanoparticles and the electrostatic interactions between the nanoparticles and the cells determine their toxic effects and biocompatibility. Previous studies showed that the nanomaterials at a small dose show biocompatibility. However, the higher dose of nanomaterials poses serious threats to normal or healthy cells. ${ }^{89,90}$

It is a matter of fact that plant-based SeNPs' potential against plant pathogens and foodborne pathogens has not been given proper consideration. However, by keeping in mind the considerable antimicrobial potential of the plantmediated SeNPs it is not very hard to believe that the SeNPs could be employed in the agriculture sector against various microbes to overcome food shortage and malnutrition. This will not only enhance the importance of SeNPs but also vast the area of applicability of SeNPs.

\section{Anti-Leishmanial, Anti-Malarial and Anti-Dengue Application Potential of SeNPs}

Leishmaniasis are the group of diseases caused by various protozoan parasites from more than twenty leishmania species which are transmitted to humans through the bites of infected female Phlebotomine sandflies and are associated with large scale morbidity and mortality. ${ }^{91}$ According to the world health organization, leishmaniasis affects more than 12 million people globally. ${ }^{25,27}$ Similarly, malaria is a dangerous disease caused by the genus Plasmodium a protozoan parasite and it is transmitted to humans through

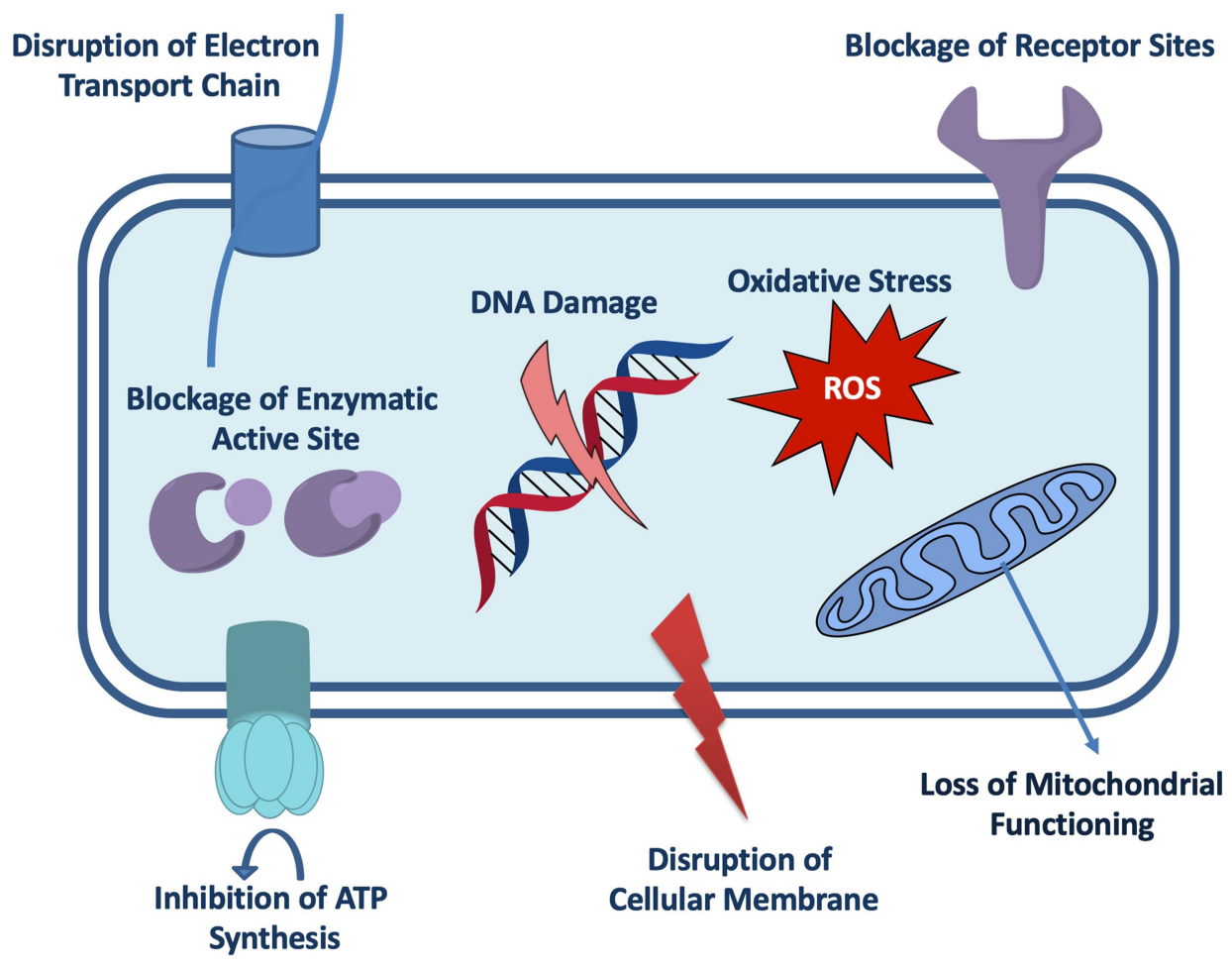

Figure 7 Possible antimicrobial mechanism of the plant-based SeNPs. 
the infected female mosquito. ${ }^{92}$ The World health organization reported 216 million cases of malaria with 445,000 deaths worldwide. ${ }^{93}$

Dengue is a viral infection caused by the bite of a mosquito with varied manifestations and progression. It is caused by the dengue virus and Aedes aegypti is a primary vector. ${ }^{94}$ However, recent reports indicate 390 million people are infected globally per year and only 96 million people show severe symptoms and nearly 20,000 infected individuals die. ${ }^{93,95}$ Various kinds of drugs have been used to treat such devastating diseases but these having the problems of being costly and toxic. To overcome the serious side effects of drugs, nanobiotechnology can be a possible and effective solution to treat these deadliest diseases. ${ }^{62}$ The plant-based SeNPs because of their non-toxic nature, excellent biocompatibility and unique bioactive properties can be one of the alternative strategies to control these devastating diseases. ${ }^{5,17,41,72}$

In recent literature, the plant-based SeNPs have been explored to control the larva of mosquitoes. In another study, it was revealed that Dillenia indica leaf extract mediated SeNPs are effective against mosquito vectors such as Aedes aegypti and Culex quinquefasciatus. 31,42,96 The toxicity of the plant-based SeNPs on larva and pupa of mosquito species are may be due to their toxic effects on cellular pathways and on other peripheral or neighboring cells. ${ }^{42}$ It was also revealed that the toxicity of the plantbased SeNPs is may be due to the denaturation of vital components and essential enzymes which ultimately reduces the membrane permeability and block the ATP synthesis and eventually leads to cell death. ${ }^{97}$ In another study, it was manifested that the SeNPs were prepared by using Clausena dentata plant extract and their different concentrations were applied to check their efficacy against different larvae like Culex quinquefasciatus, Aedes Aegypti and Anopheles stephensi. ${ }^{31}$ Interestingly, the plants-based SeNPs were found very effective with strong mosquito repellent and larvicidal potential in a dose-dependent manner. ${ }^{96}$ Another mechanism for which the plant-based SeNPs are known for the larvicidal potential is that the SeNPs causes denaturation of special sulfur-containing proteins and phosphorus-containing compounds like DNA and causes denaturation of organelles ultimately reduces membrane permeability, reduces or disrupt ATP synthesis which eventually leads to cell death. ${ }^{31,42}$

Unfortunately, the plant-based SeNPs are not much explored for their commercialization purposes. In some studies, it was reported that the several phytochemical groups like, steroids, terpenoids, essential oils, phenolics and alkaloids from different plant extracts have been explored for their insecticidal activities. ${ }^{98}$ This concept provides us a very clear future direction that the efficacies of plant-based SeNPs can be enhanced by conjugating them with the plant secondary metabolite that requires extensive in vivo studies for commercialization purposes. ${ }^{31}$ The biosynthesized SeNPs can also be used as an advanced therapeutic agent to treat cutaneous leishmaniasis. SeNPs successfully inhibit the proliferation of amastigote and promastigote which are the forms of Leishmania major in the animal models. ${ }^{99}$ Furthermore, the biocidal mechanism of the biogenic SeNPs involves inhibition of essential but unique enzymes like, cysteine protease enzymes, trypanothione reductases and trypanothione synthetase which are responsible for the leishmanial survival. ${ }^{11}$ Keeping in view, the excellent biocompatible nature of biogenic SeNPs it is not very hard to believe that plant-based SeNPs can be used as a novel therapeutic agent to control leishmania, dengue and malaria.

\section{Antiviral Application Potential of Plant-Based SeNPs}

Viral infectious diseases have posed serious threats to human health. For example, Enterovirus-71 (EV71) causes hand- foot- and mouth diseases and has become a serious public health challenge worldwide. ${ }^{100}$ Similarly, the influenza virus is still a highly contagious pathogen that affects thousands of people in various seasonal epidemics. ${ }^{101}$

Various kinds of antiviral drugs have been developed as a primary source to block the emergence of new virions from the cell membranes. However, the use of synthetic drugs has resulted in the development of drug-resistant viral strains which cause severe problems to the humans' health. ${ }^{102}$ Additionally, drug tolerance weakens the antiviral potential of synthetic antiviral drugs. ${ }^{103}$ However, this situation requires the rapid development of innovative technologies to tackle this alarming situation. Recently the synthesis of diverse nanomaterials has prompted them to be a supreme choice for the treatment of viral infectious diseases. The biosynthesized SeNPs have been proven to exhibit excellent antiviral properties. Selenium is an important trace element that controls some vital biological processes, specific enzyme modulations and has the potential to eliminate the reactive oxygen species (Figure 8). ${ }^{104}$

The selenium deficiency could cause severe susceptibility to viral infections due to the significant role of selenium 


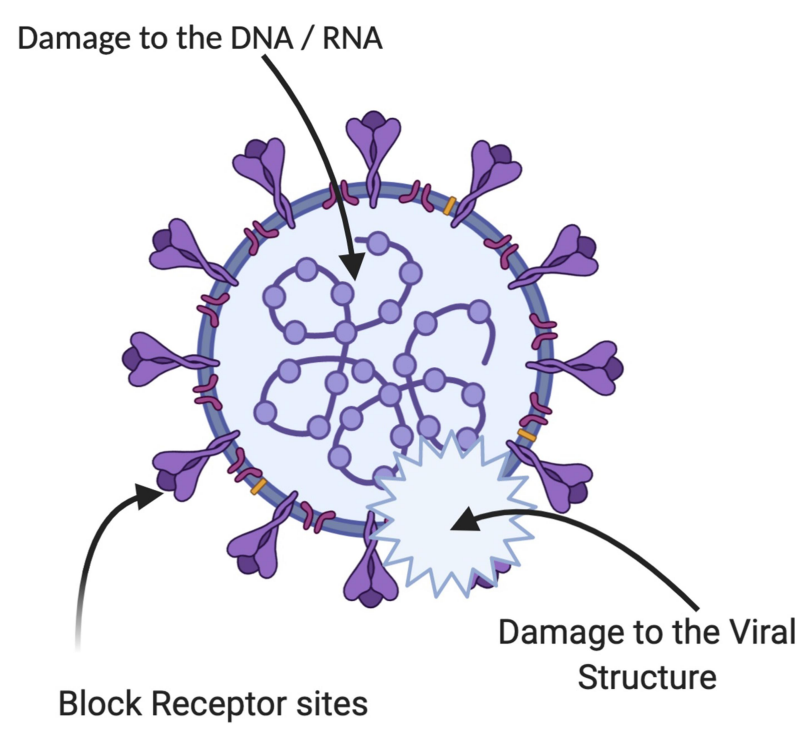

Figure 8 Possible antiviral mechanism of the plant-based SeNPs.

in the immune system and defense mechanisms. The SeNPs also have the potential to inhibit the replication of DNA and transcription of the hepatitis B virus. Unfortunately, very few research studies have reported the antiviral potential of the plant-based SeNPs. However, the biogenic SeNPs have attracted considerable attention with their specific antimicrobial potential as an integral part of selenoproteins. ${ }^{1,6}$ A study has reported the antiviral potential of SeNPs against the influenza virus. It was confirmed experimentally that the oseltamivir decorated SeNPs have the potential to trigger the generation of ROS that mediated the caspase-3 apoptosis. The ROS also regulated their level to activate Akt and P53 signaling pathways to prevent the further proliferation of cancerous cells. ${ }^{105}$

\section{Hepatoprotective Application Potential of Plant-Based SeNPs}

The liver is the most important organ of the animal body that performs various metabolic activities and is prone to severe injuries. ${ }^{10}$ The hepatocyte injuries are not only the main problem of humans but it is also a very important infirmity of the aquaculture species like fishes which suffer from liver color changes and liver enlargements. ${ }^{73}$ Different analgesic and pyretic drugs such as acetaminophen (APAP) have been successfully used against hepatic injuries in humans. APAP drug is very safe and effective. However, the overdose of the APAP induces acute nephrotoxicity and hepatotoxicity. ${ }^{7,88,106,107}$

Two molecular mechanisms are postulated for the induction of severe toxicity of kidney and liver by APAP. The first molecular mechanism involves the increased accumulation of $\mathrm{N}$-acetyl-p-benzoquinone imine (NAPQI) which is a highly reactive intermediate produced through the oxidation of APAP by cytochrome 2E1 (CYP3A4 and CYP2E1) and $\mathrm{P} 450$ 3A4 which in turns interact with the important cellular proteins and initiates toxicity in liver and kidney. ${ }^{107,108}$ Another molecular mechanism of APAP toxicity is considered independent of NAPQI formation which involves an increase in the reactive nitrogen species (RNS) such as peroxynitrites and nitric oxide (NO). ${ }^{65}$ An increased level of RNS, in turn, results in the nitration of proteins and ultimately causes protein degradation. ${ }^{64,109}$ These stresses cause mitochondrial dysfunctionality that includes the loss of mitochondrial membrane potential, inhibition of respiration and increased mitochondrial oxidative stress. ${ }^{65,78,106,107,109}$ The endpoint of such mitochondrial dysfunction ultimately starts the initiation of necrosis and apoptosis in the kidney and liver due to APAP overdose. $^{7,78,88}$

Recent nanotechnological interventions in nanomedicine brought the attention of scientific researchers and clinicians to develop a possible efficacious solution of devastating liver diseases through the plant-based SeNPs. In this scenario, Spermacoce hispida aqueous extract mediated SeNPs (Sh-SeNPs) were studied for their hepatoprotective effects against APAP toxicity because of their antioxidant potential in particularly induction of glutathione peroxidase (GPx) and glutathione (GSH) content. $^{7,18,19,62,110}$ The plant-based SeNPs were conjugated with a biologically active ligand called S-allyl-glutathione (SAG) to produce (SAG-Sh-SeNPs) to increase its biological activity. It was demonstrated that the SAGSh-SeNPs protected the mitochondrial function which resulted in the protection of the kidney and liver against APAP toxicity. ${ }^{19}$

Additionally, the chitosan-stabilized (CS) SeNPs also have been explored for their hepatoprotective potential. The CS-SeNPs alleviated the hepatocyte necrosis in the mice and decreased the serum alanine transaminase, lactic dehydrogenase and aspartate transaminase in diseased mice. It was confirmed that the SeNPs protect hepatocyte necrosis by retarding lipid oxidation and boosting the activities of glutathione peroxidase, catalase and superoxide dismutase. ${ }^{10}$ Keeping in mind the importance of CSSeNPs to control the hepatoprotective damage in mice, it is well agreed upon that the plant-based SeNPs can be a useful and efficient hepatoprotective potential tool in the future to treat human hepatocyte injuries. 
A very few research studies have been performed to report the effects of the plant-based SeNPs on human hepatocyte injuries and other liver disorders so it is the need of the hour to explore these plants-based SeNPs to protect the liver from different hepatic injuries.

\section{Application Potential of SeNPs in Detection of Heavy Metals to Bioremediate the Ecosystem}

In recent decades, due to the rapid industrial development, more and more life-threatening heavy metals have been emitted into the environment. ${ }^{111}$ These heavy metals are mostly non-biodegradable, carcinogenic, highly toxic and even at a very low concentration, can enter the food chain. ${ }^{112,113}$ Therefore it is an emergency and inevitable need to remove highly toxic heavy metals from the soil groundwater reservoirs. For example, Cadmium is one of the toxic heavy metals that is released into the environment through electroplating, photography, metals production and manufacturing of batteries. ${ }^{113,114}$ In previous studies, it has been revealed that cadmium exposure can lead to skeletal deformity, muscular cramps, renal degradation and death in humans and mammals. ${ }^{1,115}$ The United Kingdom's Department for Environment, Food and Rural Affairs has listed cadmium in the red list of priority pollutants and the Dangerous Substances Directive in the European Economic Community has been included cadmium in the blacklist. ${ }^{113}$

Similarly, the exposure to the nickel (Ni) compounds causes a variety of detrimental side effects on human health such as cardiovascular and kidney diseases, allergy, lung fibrosis, nasal cancer, and dermatitis. Therefore, there are various methods for heavy metals removal from wastewater including coagulation-flocculation, membrane filtration, electrolysis, chemical precipitation, and adsorption. ${ }^{116}$ Among all these methods, adsorption is more flexible and easy with low operational cost and significant efficiency in the heavy metals ions removal from solution. ${ }^{111}$ There are various kinds of adsorbents such as bamboo charcoal, ${ }^{113}$ root cell wall ${ }^{115}$ and activated carbon, ${ }^{20}$ which have been studied in recent decades. However, those adsorbents are usually less efficient and less effective. There is still a need for extensive research to explore the adsorbents with lower cost, faster kinetics, and higher adsorption capacity. In recent decades SeNPs have attracted a great deal of attention of researchers. Recently some studies reported the use of SeNPs as an antimicrobial agent, fertilizer, semiconductor, and sensor. ${ }^{117}$ It was reported that SeNPs can be used as an effective adsorbent for the removal of heavy metals from the contaminated solution due to their small size, negative surface charge, and large specific surface area. Furthermore, it was reported that the biosynthesized SeNPs have been used successfully to remediate zinc, copper and nickel from the contaminated soil. Unfortunately, no scientific research has been explored reporting the effects of plants-based SeNPs for the bioremediation of heavy metals. However, in other studies biosynthesized SeNPs have been applied for the removal of elemental mercury from the air and soil. ${ }^{18-120}$

Additionally, in another study, it was reported that the biogenic SeNPs have been used to bioremediate elemental mercury from the groundwater. ${ }^{118}$ Keeping in view the biocompatibility and less toxic nature of biosynthesized SeNPs, it is not very hard to believe that plant-based SeNPs can be an alternative strategy to biologically remove the harmful heavy metals from the contaminated groundwater, soil and air.

\section{Other Applications of Plant-Based SeNPs}

The plants-based SeNPs were also reported to have various other biomedical application potentials such as photocatalytic activities, ${ }^{23}$ biofortification of crops, ${ }^{121}$ nanofertilizers, ${ }^{122}$ and anti-inflammatory effects. ${ }^{1}$ A recent study has reported the potential use of SeNPs as a neuroprotective agent by modulating the inflammatory and metabolic signaling to treat ischemic cerebral stroke. ${ }^{123}$ It was also reported that the SeNPs have the potential to treat ischemiareperfusion injuries. ${ }^{124}$ In another study, it was also reported that the green synthesized SeNPs play a significant role to treat neurodegenerative disorders such as Alzheimer's disease. ${ }^{82}$ Not only this, but the plant-based rod-shaped SeNPs were synthesized using lemon fruit extract as a reducing and capping agent for the development of an $\mathrm{H}_{2} \mathrm{O}_{2}$ sensor. Hydrogen peroxide sensing is a very important aspect because it plays important role in triggering various cellar functions. ${ }^{45}$

\section{Conclusion and Future Perspectives}

The biogenesis of nanomaterials to develop formulations hold considerable potential in the 21 st century to control ailments by designing smart drug delivery platforms to deliver drugs to the targeted sites. It was reported that a significant number of nanobiotechnology based products are available in the markets. Looking at the significance of plant-based SeNPs and the green synthesis routes for 
biocompatibility and safety, it is anticipated that plants based SeNPs has emerged as a major therapeutic tool that has the potential to treat deadly cancers and many other devastating disorders ranging from, neurodegenerative diseases, diabetes, viral infections, antimicrobial drugs resistance, antifungal drugs and environmental applications. Keeping in view the excellent potency and biocompatibility and at the same time antimicrobial potential, it is not very hard to believe that the plant-based SeNPs may appear effective to develop commercialized antimicrobial drugs. Plant-based SeNPs act as a cofactor for various antioxidant enzymes, it is also expected that these nanoparticles may revolutionize the cosmetics industries by developing antiaging and skin clearing products. Keeping in view, the immense importance of selenium to boost the immune system, it is expected that plant-based SeNPs can be used for the development of antiviral vaccines. Indeed, the plants-based SeNPs hold a prominent rationale behind many reported studies. However, detailed clinical investigations are required to understand the bridge between nano-selenium and selenium and molecular changes that are responsible for therapeutic differences. Besides, it is very important to understand the kinetics or diversity of selenoproteins in presence of plantbased SeNPs to enhance our understanding of the pharmacological effects of the plant-based SeNPs. Collaborative efforts are required from biologists, chemists, pharmacists, physicians and physicists to understand the in vivo mechanism of action of selenium nanoparticles. Such efforts will likely enhance the consumption of selenium nanoparticles in the pharmaceutical industry to design customized therapeutic medicines.

\section{Abbreviations}

SeNPs, selenium nanoparticles; $\mathrm{Na}_{2} \mathrm{SeO}_{3}$, sodium selenite; $\mathrm{H}_{2} \mathrm{SeO}_{3}$, selenious acid; $\mathrm{Na}_{2} \mathrm{O}_{3} \mathrm{SSe}$, sodium selenosulfate; SPR, surface plasmon resonance; LP-SeNPs, laminarin polysaccharides; HepG2, human liver cancer cell line; AML, acute myeloid leukemia cells; SAG, S-allyl-glutathione; PAMAM, polyamidoamine; STZ, streptozotocin; MDA, malondialdehyde; NO, nitric oxide, CAT, catalase; SOD, superoxide dismutase; ROS, reactive oxygen species; NOS, nitric oxide species; DPPH, 2,2-diphenyl-1-picrylhydrazyl; ABTS, 2,2'azino-bis(3-ethylbenzothiazoline-6-sulfonic acid; APAP, acetaminophen; NAPQI, N-acetyl-p-benzoquinone imine; RNS, reactive nitrogen species; GSH, glutathione; CS-SeNPs, chitosan-stabilized selenium nanoparticles; Ni, nickel; GPX, glutathione peroxidase; FDA,
US Food and Drug Administration; NF- $\kappa$ B, nuclear factor kappa-light-chain-enhancer of activated B cells; MAPK, mitogen activated protein kinase; ERK, extracellular-signal-regulated kinase; VEGF, vascular endothelial growth factor.

\section{Ethics Approval and Consent to Participate}

This manuscript is a review article that doesn't require prior approval.

\section{Funding}

There is no funding to report.

\section{Disclosure}

The authors declare no conflicts of interest.

\section{References}

1. Khurana A, Tekula S, Saifi MA, Venkatesh P, Godugu C. Therapeutic applications of selenium nanoparticles. Biomed Pharmacother. 2019;111(September 2018):802-812. doi:10.1016/j. biopha.2018.12.146

2. Husen A, Siddiqi KS. Plants and microbes assisted selenium nanoparticles: characterization and application. $J$ Nanobiotechnology. 2014;12(1):1-10. doi:10.1186/s12951-014-0028-6

3. Hosnedlova B, Kepinska M, Skalickova S, et al. Nano-selenium and its nanomedicine applications: a critical review. Int J Nanomedicine. 2018;13:2107-2128. doi:10.2147/IJN.S157541

4. Zhang W, Chen Z, Liu H, Zhang L, Gao P, Li D. Biosynthesis and structural characteristics of selenium nanoparticles by Pseudomonas alcaliphila. Colloids Surf B Biointerfaces. 2011;88 (1):196-201. doi:10.1016/j.colsurfb.2011.06.031

5. Jin Y, Cai L, Yang Q, et al. Anti-leukemia activities of selenium nanoparticles embedded in nanotube consisted of triple-helix $\beta$ D-glucan. Carbohydr Polym. 2020;240(April):116329. doi:10.1016/j.carbpol.2020.116329

6. Esmaeili S, Fazelifard RS, Ahmadzadeh S, Shokouhi M. The importance of selenium to human health. Lancet. 2000;356 (7):233-241. doi:10.1016/S0140-6736(00)02490-9

7. Amin KA, Hashem KS, Alshehri FS, Awad ST, Hassan MS. Antioxidant and hepatoprotective efficiency of selenium nanoparticles against acetaminophen-induced hepatic damage. Biol Trace Elem Res. 2017;175(1):136-145. doi:10.1007/s12011016-0748-6

8. Gao F, Yuan Q, Gao L, et al. Cytotoxicity and therapeutic effect of irinotecan combined with selenium nanoparticles. Biomaterials. 2014;35(31):8854-8866. doi:10.1016/j.biomaterials.2014.07.004

9. Agarwal R, Behari JR. Effect of selenium pretreatment in chronic mercury intoxication in rats. Bull Environ Contam Toxicol. 2007;79(3):306-310. doi:10.1007/s00128-007-9226-3

10. Bai K, Hong B, He J, Huang W. Antioxidant capacity and hepatoprotective role of chitosan-stabilized selenium nanoparticles in concanavalin a-induced liver injury in mice. Nutrients. 2020;12 (3):857. doi:10.3390/nu12030857

11. Akbari M, Oryan A, Hatam G. Application of nanotechnology in treatment of leishmaniasis: a review. Acta Trop. 2017;172 (April):86-90. doi:10.1016/j.actatropica.2017.04.029 
12. Alam H, Khatoon N, Raza M, Ghosh PC, Sardar M. Synthesis and characterization of nano selenium using plant biomolecules and their potential applications. Bionanoscience. 2019;9 (1):96-104. doi:10.1007/s12668-018-0569-5

13. El-Ramady HR, Domokos-Szabolcsy É, Abdalla NA, et al. Selenium and nano-selenium in agroecosystems. Environ Chem Lett. 2014;12(4):495-510. doi:10.1007/s10311-014-0476-0

14. Liu Y, Zeng S, Liu Y, et al. Synthesis and antidiabetic activity of selenium nanoparticles in the presence of polysaccharides from Catathelasma ventricosum. Int $J$ Biol Macromol. 2018;114:632-639. doi:10.1016/j.ijbiomac.2018.03.161

15. Vera P, Echegoyen Y, Canellas E, et al. Nano selenium as antioxidant agent in a multilayer food packaging material. Anal Bioanal Chem. 2016;408(24):6659-6670. doi:10.1007/s00216016-9780-9

16. Singh M, Sharma N, Paras HS, Hans NS, Singh NP, Sarin A. Antioxidative potential of Phyllanthus emblica for oxidation stability of biodiesels. Environ Prog Sustain Energy. 2019;38 (2):721-726. doi:10.1002/ep.13006

17. Anu K, Singaravelu G, Murugan K, Benelli G. Green-synthesis of selenium nanoparticles using garlic cloves (Allium sativum): biophysical characterization and cytotoxicity on vero cells. J Clust Sci. 2017;28(1):551-563. doi:10.1007/s10876-016-1123-7

18. Deng G, Chen C, Zhang J, et al. Se@SiO 2 nanocomposites attenuate doxorubicin-induced cardiotoxicity through combatting oxidative damage. Artif Cells Nanomed Biotechnol. 2018;46 (sup2):112-121. doi:10.1080/21691401.2018.1452250

19. Krishnan V, Loganathan C, Thayumanavan P. Green synthesized selenium nanoparticle as carrier and potent delivering agent of s-allyl glutathione: anticancer effect against hepatocarcinoma cell line (HepG2) through induction of cell cycle arrest and apoptosis. J Drug Deliv Sci Technol. 2019;53(May):101207. doi:10.1016/j. jddst.2019.101207

20. An HK, Park BY, Kim DS. Crab shell for the removal of heavy metals from aqueous solution. Water Res. 2001;35 (15):3551-3556. doi:10.1016/S0043-1354(01)00099-9

21. Fardsadegh B, Vaghari H, Mohammad-Jafari R, Najian Y, Jafarizadeh-Malmiri H. Biosynthesis, characterization and antimicrobial activities assessment of fabricated selenium nanoparticles using Pelargonium zonale leaf extract. Green Process Synth. 2019;8(1):191-198. doi:10.1515/gps-2018-0060

22. Cui D, Liang T, Sun L, et al. Green synthesis of selenium nanoparticles with extract of hawthorn fruit induced hepg2 cells apoptosis. Pharm Biol. 2018;56(1):528-534. doi:10.1080/ 13880209.2018.1510974

23. Alagesan V, Venugopal S. Green synthesis of selenium nanoparticle using leaves extract of withania somnifera and its biological applications and photocatalytic activities. Bionanoscience. 2019;9 (1):105-116. doi:10.1007/s12668-018-0566-8

24. Ingole AR, Thakare SR, Khati NT, Wankhade AV, Burghate DK. Green synthesis of selenium nanoparticles under ambient condition. Chalcogenide Lett. 2010;7(7):485-489.

25. Javed B, Raja NI, Nadhman A, Mashwani Z-R. Understanding the potential of bio-fabricated non-oxidative silver nanoparticles to eradicate Leishmania and plant bacterial pathogens. Appl Nanosci. 2020;10(6):2057-2067. doi:10.1007/s13204-02001355-5

26. Javed B, Mashwani ZUR. Phytosynthesis of colloidal nanosilver from mentha longifolia and mentha arvensis: comparative morphological and optical characterization. Microsc Res Tech. 2020;83:1-9. doi:10.1002/jemt.23518

27. Javed B, Nadhman A, Mashwani Z-U-R. Phytosynthesis of Ag nanoparticles from mentha longifolia: their structural evaluation and therapeutic potential against HCT116 colon cancer, Leishmanial and bacterial cells. Appl Nanosci. 2020;10 (9):3503-3515. doi:10.1007/s13204-020-01428-5
28. Javed B, Nadhman A, Mashwani Z. Optimization, characterization and antimicrobial activity of silver nanoparticles against plant bacterial pathogens phyto-synthesized by mentha longifolia. Mater Res Express. 2020;7(8):085406. doi:10.1088/ 2053-1591/abaf19

29. Javed B, Nadhman A, Razzaq A, Mashwani Z. One-pot phytosynthesis of nano-silver from mentha longifolia L.: their characterization and evaluation of photodynamic potential. Mater Res Express. 2020;7(5):1-9. doi:10.1088/2053-1591/ab903b

30. Javed B, Mashwani ZUR. Synergistic effects of physicochemical parameters on bio-fabrication of mint silver nanoparticles: structural evaluation and action against HCT116 colon cancer cells. Int J Nanomedicine. 2020;15:3621-3637. doi:10.2147/IJN.S254402

31. Sowndarya P, Ramkumar G, Shivakumar MS. Green synthesis of selenium nanoparticles conjugated Clausena dentata plant leaf extract and their insecticidal potential against mosquito vectors. Artif Cells Nanomed Biotechnol. 2017;45(8):1490-1495. doi:10.1080/21691401.2016.1252383

32. Kora AJ, Rastogi L. Biomimetic synthesis of selenium nanoparticles by Pseudomonas aeruginosa ATCC 27853: an approach for conversion of selenite. J Environ Manage. 2016;181:231-236. doi:10.1016/j.jenvman.2016.06.029

33. Zhang SY, Zhang J, Wang HY, Chen HY. Synthesis of selenium nanoparticles in the presence of polysaccharides. Mater Lett. 2004;58(21):2590-2594. doi:10.1016/j.matlet.2004.03.031

34. Langi B, Shah C, Singh K, Chaskar A, Kumar M, Bajaj PN. Ionic liquid-induced synthesis of selenium nanoparticles. Mater Res Bull. 2010;45(6):668-671. doi:10.1016/j.materresbull.2010.03.005

35. Khan T, Ullah N, Khan MA, Mashwani ZUR, Nadhman A. Plantbased gold nanoparticles; a comprehensive review of the decade-long research on synthesis, mechanistic aspects and diverse applications. $A d v$ Colloid Interface Sci. 2019;272:102017. doi:10.1016/j.cis.2019.102017

36. Zhang H, Zhou H, Bai J, et al. Biosynthesis of selenium nanoparticles mediated by fungus Mariannaea sp. HJ and their characterization. Colloids Surf a Physicochem Eng Asp. 2019;571 (November2018):9-16. doi:10.1016/j.colsurfa.2019.02.070

37. Shakibaie M, Rezaie S, Abdollahi M, Shahverdi AR Biosynthesis of selenium nanoparticles using Klebsiella pneumoniae and their recovery by a simple sterilization process. Braz J Microbiol. 2010;41:461-466. doi:10.1590/S151783822010000200028

38. Fardsadegh B, Jafarizadeh-Malmiri H. Aloe vera leaf extract mediated green synthesis of selenium nanoparticles and assessment of their in vitro antimicrobial activity against spoilage fungi and pathogenic bacteria strains. Green Process Synth. 2019;8 (1):399-407. doi:10.1515/gps-2019-0007

39. Ahmadi O, Jafarizadeh-Malmiri H, Jodeiri N. Eco-friendly microwave-enhanced green synthesis of silver nanoparticles using Aloe vera leaf extract and their physico-chemical and antibacterial studies. Green Process Synth. 2018;7(3):231-240. doi:10.1515/gps-2017-0039

40. Sánchez-Machado DI, López-Cervantes J, Sendón R, SanchesSilva A. Aloe vera: ancient knowledge with new frontiers. Trends Food Sci Technol. 2017;61:94-102. doi:10.1016/j. tifs.2016.12.005

41. Sharma G, Sharma AR, Bhavesh R, et al. Biomolecule-mediated synthesis of selenium nanoparticles using dried vitis vinifera (raisin) extract. Molecules. 2014;19(3):2761-2770. doi:10.3390/ molecules19032761

42. Krishnan M, Ranganathan K, Maadhu P, Thangavelu P, Kundan S, Arjunan N. Leaf extract of Dillenia indica as a source of selenium nanoparticles with larvicidal and antimicrobial potential toward vector mosquitoes and pathogenic microbes. Coatings. 2020;10(7):1-16. doi:10.3390/coatings10070626 
43. Menon S, Shrudhi SD, Agarwal H, Shanmugam VK. Efficacy of biogenic selenium nanoparticles from an extract of ginger towards evaluation on anti-microbial and anti-oxidant activities. Colloids Interface Sci Commun. 2019;29(November2018):1-8. doi:10.1016/ j.colcom.2018.12.004

44. Rajasekar S, Kuppusamy S. Eco-friendly formulation of selenium nanoparticles and its functional characterization against breast cancer and normal cells. J Clust Sci. 2020;0123456789. doi:10.1007/s10876-020-01856-x

45. Sawant VJ, Sawant VJ. Biogenic capped selenium nano rods as naked eye and selective hydrogen peroxide spectrometric sensor. Sens Bio-Sensing Res. 2020;27(November2019):100314. doi:10.1016/j.sbsr.2019.100314

46. Fan D, Li L, Li Z, et al. Biosynthesis of selenium nanoparticles and their protective, antioxidative effects in streptozotocin induced diabetic rats. Sci Technol Adv Mater. 2020. doi:10.1080/14686996.2020.1788907

47. Sadalage PS, Nimbalkar MS, Sharma KKK, Patil PS, Pawar KD. Sustainable approach to almond skin mediated synthesis of tunable selenium microstructures for coating cotton fabric to impart specific antibacterial activity. $J$ Colloid Interface Sci. 2020;569:346-357. doi:10.1016/j.jcis.2020.02.094

48. Liang T, Qiu X, Ye X, et al. Biosynthesis of selenium nanoparticles and their effect on changes in urinary nanocrystallites in calcium oxalate stone formation. 3 Biotech. 2020;10(1):1-6. doi:10.1007/s13205-019-1999-7

49. Damyanov CA, Maslev IK, Pavlov VS. Conventional treatment of cancer realities and problems. Ann Complement Altern Med. 2018;1(1):1-9.

50. Nounou MI, Elamrawy F, Ahmed N, Abdelraouf K, Goda S, Syed-Sha-Qhattal H. Breast cancer: conventional diagnosis and treatment modalities and recent patents and technologies supplementary issue: targeted therapies in breast cancer treatment. Breast Cancer Basic Clin Res. 2015;9:17-34. doi:10.4137/ BCBCR.S29420

51. Langer R. Biomaterials in drug delivery and tissue engineering: one laboratory's experience. Acc Chem Res. 2000;33(2):94-101. doi:10.1021/ar9800993

52. Farokhzad OC, Langer R. Nanomedicine: developing smarter therapeutic and diagnostic modalities. Adv Drug Deliv Rev. 2006;58(14):1456-1459. doi:10.1016/j.addr.2006.09.011

53. Farokhzad OC, Langer R. Impact of nanotechnology on drug delivery. ACS Nano. 2009;3(1):16-20. doi:10.1021/nn900002m

54. Alexis F, Pridgen E, Molnar LK, Farokhzad OC. Factors affecting the clearance and biodistribution of polymeric nanoparticles. $\mathrm{Mol}$ Pharm. 2008;5:505-515. doi:10.1021/mp800051m

55. Ramamurthy $\mathrm{CH}$, Sampath KS, Arunkumar P, et al. Green synthesis and characterization of selenium nanoparticles and its augmented cytotoxicity with doxorubicin on cancer cells. Bioprocess Biosyst Eng. 2013;36(8):1131-1139. doi:10.1007/s00449-012-0867-1

56. Schneider T, Mawrin C, Scherlach C, Skalej M, Firsching R. Gliomas in adults. Dtsch Arztebl. 2010;107(45):799-808. doi:10.3238/arzteb1.2010.0799

57. Cui D, Ma J, Liang T, et al. Selenium nanoparticles fabricated in laminarin polysaccharides solutions exert their cytotoxicities in HepG2 cells by inhibiting autophagy and promoting apoptosis. Int $J$ Biol Macromol. 2019;137:829-835. doi:10.1016/j. ijbiomac.2019.07.031

58. Zeebaree SYS, Zeebaree AYS, Zebari OIH. Diagnosis of the multiple effect of selenium nanoparticles decorated by Asteriscus graveolens components in inhibiting HepG2 cell proliferation. Sustain Chem Pharm. 2020;15(September2019):100210. doi:10.1016/j. scp.2019.100210

59. Mittal AK, Chisti Y, Banerjee UC. Synthesis of metallic nanoparticles using plant extracts. Biotechnol Adv. 2013;31 (2):346-356. doi:10.1016/j.biotechadv.2013.01.003
60. Maiyo F, Singh M. Selenium nanoparticles: potential in cancer gene and drug delivery. Nanomedicine. 2017;12(9):1075-1089. doi:10.2217/nnm-2017-0024

61. Qiu WY, Wang YY, Wang M, Yan JK. Construction, stability, and enhanced antioxidant activity of pectin-decorated selenium nanoparticles. Colloids Surf $B$ Biointerfaces. 2018;170: (March):692-700. doi:10.1016/j.colsurfb.2018.07.003

62. Vennila K, Chitra L, Balagurunathan R, Palvannan T. Comparison of biological activities of selenium and silver nanoparticles attached with bioactive phytoconstituents: green synthesized using Spermacoce hispida extract. Adv Nat Sci Nanosci Nanotechnol. 2018;9:1. doi:10.1088/2043-6254/aa9f4d

63. Zheng W, Cao C, Liu Y, et al. Multifunctional polyamidoamine-modified selenium nanoparticles dual-delivering siRNA and cisplatin to A549/DDP cells for reversal multidrug resistance. Acta Biomater. 2015;11(1):368-380. doi:10.1016/j.actbio.2014.08.035

64. Hinson JA, Bucci TJ, Irwin LK, Michael SL, Mayeux PR. Effect of inhibitors of nitric oxide synthase on acetaminophen-induced hepatotoxicity in mice. Nitric Oxide Biol Chem. 2002;6 (2):160-167. doi:10.1006/niox.2001.0404

65. Nahdi AMTA, John A, Raza H. Elucidation of molecular mechanisms of streptozotocin-induced oxidative stress, apoptosis, and mitochondrial dysfunction in Rin-5F pancreatic $\beta$-cells. Oxid Med Cell Longev. 2017;2017:1-15. doi:10.1155/2017/7054272

66. Vieira R, Souto SB, Sánchez-López E, et al. Sugar-lowering drugs for type 2 diabetes mellitus and metabolic syndromestrategies for in vivo administration: part-II. J Clin Med. 2019;8 (9):1332. doi:10.3390/jcm8091332

67. Wong CY, Al-Salami H, Dass CR. Potential of insulin nanoparticle formulations for oral delivery and diabetes treatment. J Control Release. 2017;264(August):247-275. doi:10.1016/j. jconrel.2017.09.003

68. Souto SB, Souto EB, Braga DC, Medina JL. Prevention and current onset delay approaches of type 2 diabetes mellitus (T2DM). Eur J Clin Pharmacol. 2011;67(7):653-661. doi:10.1007/s00228-011-1038-z

69. Twigg MJ, Wright D, Barton G, Kirkdale CL, Thornley T. The pharmacy care plan service: evaluation and estimate of cost-effectiveness. Res Soc Adm Pharm. 2019;15(1):84-92. doi:10.1016/j.sapharm.2018.03.062

70. Gedawy A, Martinez J, Al-Salami H, Dass CR. Oral insulin delivery: existing barriers and current counter-strategies. $J$ Pharm Pharmacol. 2018;70(2):197-213. doi:10.1111/ jphp. 12852

71. É U, Monori I, Megyeri A, et al. Protective effects of meat from lambs on selenium nanoparticle supplemented diet in a mouse model of polycyclic aromatic hydrocarbon-induced immunotoxicity. Food Chem Toxicol. 2014;64:298-306. doi:10.1016/j.fct.2013.12.004

72. Wadhwani SA, Shedbalkar UU, Singh R, Chopade BA. Biogenic selenium nanoparticles: current status and future prospects. Appl Microbiol Biotechnol. 2016;100(6):2555-2566. doi:10.1007/ s00253-016-7300-7

73. Kunjiappan S, Bhattacharjee C, Chowdhury R. In vitro antioxidant and hepatoprotective potential of Azolla microphylla phytochemically synthesized gold nanoparticles on acetaminophen - induced hepatocyte damage in Cyprinus carpio L. In Vitro Cell Dev Biol Anim. 2015;51(6):630-643. doi:10.1007/s11626-014-9841-3

74. Khalil I, Yehye WA, Etxeberria AE, et al. Nanoantioxidants: recent trends in antioxidant delivery applications. Antioxidants. 2020;9:1. doi:10.3390/antiox9010024

75. Menon S, Shanmugam VK. Cytotoxicity analysis of biosynthesized selenium nanoparticles towards A549 lung cancer cell line. $J$ Inorg Organomet Polym Mater. 2020;30(5):1852-1864. doi:10.1007/s10904-019-01409-4 
76. Gunti L, Dass RS, Kalagatur NK. Phytofabrication of selenium nanoparticles from emblica officinalis fruit extract and exploring its biopotential applications: antioxidant, antimicrobial, and biocompatibility. Front Microbiol. 2019;10(APR):1-17. doi:10.3389/fmicb.2019.00931

77. Zhang W, Zhang J, Ding D, et al. Synthesis and antioxidant properties of Lycium barbarum polysaccharides capped selenium nanoparticles using tea extract. Artif Cells Nanomed Biotechnol. 2018;46(7):1463-1470. doi:10.1080/21691401.2017.1373657

78. Du K, Farhood A, Jaeschke H. Mitochondria-targeted antioxidant mito-tempo protects against acetaminophen hepatotoxicity. Arch Toxicol. 2017;91(2):761-773. doi:10.1007/s00204-016-1692-0

79. Kalishwaralal K, Jeyabharathi S, Sundar K, Selvamani S, Prasanna M, Muthukumaran A. A novel biocompatible chitosan-Selenium nanoparticles (SeNPs) film with electrical conductivity for cardiac tissue engineering application. Mater Sci Eng C. 2018;92(October2017):151-160. doi:10.1016/j.msec.2018.06.036

80. Abalaka ME, Daniyan SY, Mann A. Evaluation of the antimicrobial activities of two Ziziphus species (Ziziphus mauritiana L. and Ziziphus spinachristi L.) on some microbial pathogens. Afr J Pharm Pharmacol. 2010;4(4):135-139.

81. Singh R, Sripada L, Singh R. Side effects of antibiotics during bacterial infection: mitochondria, the main target in host cell. Mitochondrion. 2014;16:50-54. doi:10.1016/j.mito.2013.10.005

82. DiMauro S, Davidzon G. Mitochondrial DNA and disease. Ann Med. 2005;37(3):222-232. doi:10.1080/07853890510007368

83. Xing G, Chen Z, Wei Q, et al. Maternally inherited non-syndromic hearing loss associated with mitochondrial 12S rRNA A827G mutation in a Chinese family. Biochem Biophys Res Commun. 2006;344(4):1253-1257. doi:10.1016/j.bbrc.2006.04.033

84. Kim JS, Heo P, Yang TJ, et al. Bacterial persisters tolerate antibiotics by not producing hydroxyl radicals. Biochem Biophys Res Commun. 2011;413(1):105-110. doi:10.1016/j.bbrc.2011.08.063

85. Khiralla GM, El-Deeb BA. Antimicrobial and antibiofilm effects of selenium nanoparticles on some foodborne pathogens. $L W T$ Food Sci Technol. 2015;63(2):1001-1007. doi:10.1016/j. lwt.2015.03.086

86. Sonkusre P, Nanduri R, Gupta P, Cameotra SS. Improved extraction of intracellular biogenic selenium nanoparticles and their specificity for cancer chemoprevention. $J$ Nanomed Nanotechnol. 2014;5:2. doi:10.4172/2157-7439.1000194

87. Zonaro E, Lampis S, Turner RJ, Junaid S, Vallini G. Biogenic selenium and tellurium nanoparticles synthesized by environmental microbial isolates efficaciously inhibit bacterial planktonic cultures and biofilms. Front Microbiol. 2015;6(MAY):1-11. doi:10.3389/fmicb.2015.00584

88. Yan $\mathrm{M}$, Huo $\mathrm{Y}$, Yin $\mathrm{S}$, $\mathrm{Hu} \mathrm{H}$. Mechanisms of acetaminophen-induced liver injury and its implications for therapeutic interventions. Redox Biol. 2018;17(March):274-283. doi:10.1016/j.redox.2018.04.019

89. Markides H, Rotherham M, El Haj AJ. Biocompatibility and toxicity of magnetic nanoparticles in regenerative medicine. J Nanomater. 2012;2012:13-15. doi:10.1155/2012/614094

90. Li X, Wang L, Fan Y, Feng Q, Cui FZ. Biocompatibility and toxicity of nanoparticles and nanotubes. J Nanomater. 2012;2012. doi:10.1155/2012/548389

91. Maroli M, Feliciangeli MD, Bichaud L, Charrel RN, Gradoni L. Phlebotomine sandflies and the spreading of leishmaniases and other diseases of public health concern. Med Vet Entomol. 2013;27(2):123-147. doi:10.1111/j.1365-2915.2012.01034.x

92. Benelli G, Beier JC. Current vector control challenges in the fight against malaria. Acta Trop. 2017;174(June):91-96. doi:10.1016/j. actatropica.2017.06.028

93. Boniface PK, Ferreira EI. Flavonoids as efficient scaffolds: recent trends for malaria, leishmaniasis, Chagas disease, and dengue. Phyther Res. 2019;33(10):2473-2517. doi:10.1002/ptr.6383
94. Peng M, Watanabe S, Chan KWK, et al. Luteolin restricts dengue virus replication through inhibition of the proprotein convertase furin. Antiviral Res. 2017;143:176-185. doi:10.1016/j. antiviral.2017.03.026

95. Beltrán-Silva SL, Chacón-Hernández SS, Moreno-Palacios E, Pereyra-Molina JÁ. Clinical and differential diagnosis: dengue, chikungunya and Zika. Rev Med Hosp Gen (Mex). 2018;81 (3):146-153. doi:10.1016/j.hgmx.2016.09.011

96. Suganya G, Karthi S, Shivakumar MS. Larvicidal potential of silver nanoparticles synthesized from Leucas aspera leaf extracts against dengue vector Aedes aegypti. Parasitol Res. 2014;113 (3):875-880. doi:10.1007/s00436-013-3718-3

97. Soni N, Prakash S. Green nanoparticles for mosquito control. Sci World J. 2014;2014:1-6. doi:10.1155/2014/496362

98. Shaalan EAS, Canyon D, Younes MWF, Abdel-Wahab H, Mansour AH. A review of botanical phytochemicals with mosquitocidal potential. Environ Int. 2005;31(8):1149-1166. doi:10.1016/j.envint.2005.03.003

99. Beheshti N, Soflaei S, Shakibaie M, et al. Efficacy of biogenic selenium nanoparticles against Leishmania major: in vitro and in vivo studies. J Trace Elem Med Biol. 2013;27(3):203-207. doi:10.1016/j.jtemb.2012.11.002

100. Zhang F, Liu Y, Chen X, et al. RASSF4 promotes EV71 replication to accelerate the inhibition of the phosphorylation of AKT. Biochem Biophys Res Commun. 2015;458(4):810-815. doi:10.1016/j.bbrc.2015.02.035

101. Tao W, Hurst BL, Shakya AK, et al. Consensus M2e peptide conjugated to gold nanoparticles confers protection against $\mathrm{H} 1 \mathrm{~N} 1, \mathrm{H} 3 \mathrm{~N} 2$ and $\mathrm{H} 5 \mathrm{~N} 1$ influenza A viruses. Antiviral Res. 2017;141:62-72. doi:10.1016/j.antiviral.2017.01.021

102. Nguyen JT, Smee DF, Barnard DL, et al. Efficacy of combined therapy with amantadine, oseltamivir, and ribavirin in vivo against susceptible and amantadine-resistant influenza a viruses. PLoS One. 2012;7(1):1-9. doi:10.1371/journal.pone.0031006

103. Antipov EA, Pokryshevskaya EB. The effects of adverse drug reactions on patients' satisfaction: evidence from publicly available data on Tamiflu (oseltamivir). Int J Med Inform. 2019;125 (November2018):30-36. doi:10.1016/j.ijmedinf.2019.02.005

104. Li Y, Lin Z, Zhao M, et al. Multifunctional selenium nanoparticles as carriers of HSP70 siRNAto induce apoptosis of HepG2 cells. Int J Nanomedicine. 2016;11:3065-3076. doi:10.2147/IJN. S109822

105. Li Y, Lin Z, Guo M, et al. Inhibitory activity of selenium nanoparticles functionalized with oseltamivir on H1N1 influenza virus. Int J Nanomedicine. 2017;12:5733-5743. doi:10.2147/IJN.S140939

106. Kon K, Kim JS, Jaeschke H, Lemasters JJ. Mitochondrial permeability transition in acetaminophen-induced necrosis and apoptosis of cultured mouse hepatocytes. Hepatology. 2004;40 (5):1170-1179. doi:10.1002/hep.20437

107. Hu J, Ramshesh VK, McGill MR, Jaeschke H, Lemasters JJ. Low dose acetaminophen induces reversible mitochondrial dysfunction associated with transient c-Jun N-terminal kinase activation in mouse liver. Toxicol Sci. 2016;150(1):204-215. doi:10.1093/ toxsci/kfv319

108. Dahlin DC, Miwa GT, Lu AYH, Nelson SD. N-acetyl-p-benzoquinone imine: a cytochrome P-450-mediated oxidation product of acetaminophen. Isotopenpraxis. 1984;20(1):1327-1331. doi:10.1073/pnas.81.5.1327

109. Abdelmegeed MA, Jang S, Banerjee A, Hardwick JP, Song BJ. Robust protein nitration contributes to acetaminophen-induced mitochondrial dysfunction and acute liver injury. Free Radic Biol Med. 2013;60:211-222. doi:10.1016/j.freeradbiomed.2013.02.018

110. Chen L, Huang G. The antiviral activity of polysaccharides and their derivatives. Int $J$ Biol Macromol. 2018;115:77-82. doi:10.1016/j.ijbiomac.2018.04.056 
111. Jain R, Jordan N, Schild D, et al. Adsorption of zinc by biogenic elemental selenium nanoparticles. Chem Eng $J$. 2015;260:855-863. doi:10.1016/j.cej.2014.09.057

112. Li Q, Chai L, Qin W. Cadmium(II) adsorption on esterified spent grain: equilibrium modeling and possible mechanisms. Chem Eng J. 2012;197:173-180. doi:10.1016/j.cej.2012.04.102

113. Wang FY, Wang H, Ma JW. Adsorption of cadmium (II) ions from aqueous solution by a new low-cost adsorbent-Bamboo charcoal. J Hazard Mater. 2010;177(1-3):300-306. doi:10.1016/ j.jhazmat.2009.12.032

114. Semerjian L. Equilibrium and kinetics of cadmium adsorption from aqueous solutions using untreated Pinus halepensis sawdust. J Hazard Mater. 2010;173(1-3):236-242. doi:10.1016/ j.jhazmat.2009.08.074

115. Chen G, Liu Y, Wang R, Zhang J, Owens G. Cadmium adsorption by willow root: the role of cell walls and their subfractions. Environ Sci Pollut Res. 2013;20(8):5665-5672. doi:10.1007/ s11356-013-1506-3

116. Zeng L, Chen $\mathrm{Y}$, Zhang Q, et al. Adsorption of $\mathrm{Cd}(\mathrm{II}), \mathrm{Cu}(\mathrm{II})$ and $\mathrm{Ni}(\mathrm{II})$ ions by cross-linking chitosan/rectorite nano-hybrid composite microspheres. Carbohydr Polym. 2015;130:333-343. doi:10.1016/j.carbpol.2015.05.015

117. Nancharaiah YV, Lens PNL. Selenium biomineralization for biotechnological applications. Trends Biotechnol. 2015;33 (6):323-330. doi:10.1016/j.tibtech.2015.03.004

118. Wang X, Zhang D, Pan X, et al. Aerobic and anaerobic biosynthesis of nano-selenium for remediation of mercury contaminated soil. Chemosphere. 2017;170:266-273. doi:10.1016/j. chemosphere.2016.12.020
119. Fellowes JW, Pattrick RAD, Green DI, Dent A, Lloyd JR, Pearce CI. Use of biogenic and abiotic elemental selenium nanospheres to sequester elemental mercury released from mercury contaminated museum specimens. J Hazard Mater. 2011;189 (3):660-669. doi:10.1016/j.jhazmat.2011.01.079

120. Wang X, Zhang D, Qian H, Liang Y, Pan X, Gadd GM. Interactions between biogenic selenium nanoparticles and goethite colloids and consequence for remediation of elemental mercury contaminated groundwater. Sci Total Environ. 2018;613-614:672-678. doi:10.1016/j.scitotenv.2017.09.113

121. Ikram M, Raja NI, Javed B, et al. Foliar applications of bio-fabricated selenium nanoparticles to improve the growth of wheat plants under drought stress. Green Process Synth. 2020;9:706-714. doi:10.1515/gps-2020-0067

122. Gudkov SV, Shafeev GA, Glinushkin AP, et al. Production and use of selenium nanoparticles as fertilizers. ACS Omega. 2020;5 (28):17767-17774. doi:10.1021/acsomega.0c02448

123. Amani H, Habibey R, Shokri F, et al. Selenium nanoparticles for targeted stroke therapy through modulation of inflammatory and metabolic signaling. Sci Rep. 2019;9(1):1-15. doi:10.1038/ s41598-019-42633-9

124. Amani H, Habibey R, Hajmiresmail SJ, Latifi S, Pazoki-Toroudi $\mathrm{H}$, Akhavan O. Antioxidant nanomaterials in advanced diagnoses and treatments of ischemia reperfusion injuries. $J$ Mat Chem B. 2017;5(48):9452-9476. doi:10.1039/c7tb01689a

\section{Publish your work in this journal}

The International Journal of Nanomedicine is an international, peerreviewed journal focusing on the application of nanotechnology in diagnostics, therapeutics, and drug delivery systems throughout the biomedical field. This journal is indexed on PubMed Central, MedLine, CAS, SciSearch ${ }^{\circledR}$, Current Contents ${ }^{\mathbb{R}} /$ Clinical Medicine,
Journal Citation Reports/Science Edition, EMBase, Scopus and the Elsevier Bibliographic databases. The manuscript management system is completely online and includes a very quick and fair peer-review system, which is all easy to use. Visit http://www.dovepress.com/ testimonials.php to read real quotes from published authors. 